Western University

Scholarship@Western

Civil and Environmental Engineering

Civil and Environmental Engineering

Publications

Department

2015

Experimental Investigation of the Composite Action between Hollowcore Slabs with Machine Cast Finish and Concrete Topping

\author{
Aiham Adawi \\ Western University \\ Maged Youssef \\ youssef@uwo.ca \\ Mohamed E. Meshaly \\ Alexandria University
}

Follow this and additional works at: https://ir.lib.uwo.ca/civilpub

Part of the Civil and Environmental Engineering Commons

Citation of this paper:

Adawi, Aiham; Youssef, Maged; and Meshaly, Mohamed E., "Experimental Investigation of the Composite Action between Hollowcore Slabs with Machine Cast Finish and Concrete Topping" (2015). Civil and Environmental Engineering Publications. 181.

https://ir.lib.uwo.ca/civilpub/181 


\title{
EXPERIMENTAL INVESTIGATION OF THE COMPOSITE ACTION BETWEEN HOLLOWCORE SLABS WITH MACHINE CAST FINISH AND CONCRETE TOPPING
}

\author{
Aiham Adawi ${ }^{1}$, Maged A. Youssef ${ }^{*},{ }^{1}$, Mohamed E. Meshaly ${ }^{2}$ \\ ${ }^{1}$ Department of Civil and Environmental Engineering, Western University, London, Ontario, Canada, N6A 5B9 \\ ${ }^{2}$ Department of Structural Engineering, Alexandria University, Alexandria, Egypt
}

\begin{abstract}
Hollowcore slabs are precast/prestressed concrete elements produced at a manufacturing plant before shipping to the job site. Following installation, a layer of concrete topping is usually cast to connect the slabs and to have a level surface. According to current North American design standards, the topping should not be considered to act compositely with the slabs except if their surface satisfies a strict roughness requirement. This paper evaluates if such restriction is justified for hollowcore slabs with machine cast finish through an experimental program that involves pull-off, push-off and full-scale tests. The surface roughness was first evaluated. The peel (bond) and shear strengths of the interface between the slabs and the topping were then assessed using pull-off and push-off tests. Full-scale tests examined the overall behaviour of the composite system. The tested composite slabs exhibited higher tensile and shear stresses than the limits set by North American design standards. Surface roughness threshold for machine cast hollowcore slabs is estimated. The paper presents the initial evidence that hollowcore slabs with machine cast surface can be considered to act compositely with the concrete topping.
\end{abstract}

Keywords: Hollowcore, Surface Roughness, Machine Cast Finish, Composite Action, Pull-off Test, Push-off Test, Full-scale Test, Bond Strength, Shear stress.

*Corresponding Author, E-mail: youssef@uwo.ca, Phone: 519-661-2111 Ext. 88661. 


\section{INTRODUCTION}

Hollowcore slabs are used in floors and roofs of residential, industrial, and commercial buildings as well as detention centers. They are characterized by an initial camber that is formed during the prestressing process. To account for surface irregularities resulting from this camber and to connect the slabs, a layer of concrete topping is usually cast. If the interface between the topping and the slabs has adequate shear resistance, the composite action developed between the two concrete layers increases the rated capacity of the slabs. Values of $0.70 \mathrm{MPa}$ and $0.55 \mathrm{MPa}$ are specified by CSA A23.3 ${ }^{1}$ and ACI $318^{2}$, respectively, for the interface shear resistance. Intentional roughening of the slabs surface is accepted as a method to guarantee achieving such shear strength. The minimum acceptable amplitudes for such roughness are $6.35 \mathrm{~mm}$ (clauses 11.6.9 and 17.5.3.3 of ACI $318^{2}$ ) and $5.00 \mathrm{~mm}$ (explanatory note N17.4.3.2 of CSA A23.3 ${ }^{1}$ ). These amplitudes induce additional costs to hollowcore slab manufacturers. In a typical precast operation, the default surface finish for the hollowcore slabs is generally referred to as "machine cast finish". This finish, although different from manufacturer to manufacturer, has a surface roughness that does not satisfy the aforementioned requirement.

Ozell and Cochran ${ }^{3}$ tested nine prestressed composite lintel beams. The beams did not contain any horizontal shear reinforcement and had a very smooth surface. All beams maintained composite action with the topping concrete until failing in a flexural shear mode. It was

concluded that reliable horizontal shear strength can be developed without roughening. Hanson ${ }^{4}$ conducted push-off tests on concrete beams and concluded that the horizontal shear strength can reach 2.1 MPa without roughening. Hanson ${ }^{4}$ also tested a beam with a surface intentionally roughened to an amplitude of $9.5 \mathrm{~mm}$. The beam suffered significant loss of composite action before failure. The maximum horizontal shear stress between the beam and the concrete topping 
was estimated at 2.76 MPa. CTA Technical Bulletins TB74-B6 ${ }^{5}$ and $\mathrm{TB} 76-\mathrm{B} 4{ }^{6}$ presented the results for 16 prestressed composite slabs with different surface finishes and concluded that horizontal shear levels given in ACI $318^{2}$ are highly conservative. Limited experimental work has been conducted to evaluate the horizontal shear strength of composite hollowcore slabs in full-scale configuration. Girhammar and Pajari ${ }^{7}$ investigated the shear capacity of composite hollowcore slabs with machine cast finish and concluded that the composite action increased the shear capacity by $35 \%$. The surface of the tested hollowcore slabs was not treated or roughened. Mones and Breña ${ }^{8}$ conducted 24 push-off tests on hollowcore slabs with cast-in-place concrete topping to evaluate the horizontal shear strength. The slabs included dry-mix and wet-mix samples and varied in surface roughness and surface moisture condition. They concluded that the shear strength limit of $0.55 \mathrm{MPa}$ stated in the ACI $318^{2}$ code was conservative for all surface roughness types including the machine cast finish. Ibrahim et al. ${ }^{9}$ studied the horizontal shear transfer along the interface of hollowcore slabs and concrete topping using 14 specimens that vary in surface roughness. It was concluded that slip was not significant for shear forces up to 50 $\mathrm{kN}$. Their study showed poor correlation between the surface roughness of the hollowcore slabs and the obtained shear strength. Ibrahim et al. ${ }^{10}$ conducted full-scale tests on hollowcore slabs with concrete topping. They concluded that the slip in the bonded smooth specimens can be eliminated by roughening the surface of the hollowcore slabs. The research mentioned in this paragraph provided some evidence about the composite action for hollowcore slabs. However, details about slip and peel deformations, acceptable levels of peel and shear stresses and full scale composite behavior are scarce in the literature.

Adawi et al. ${ }^{11}$ experimentally examined the shear strength between roughened hollowcore slabs and the concrete topping. They have also provided details of an analytical model that can be 
utilized to understand the shear and peel behavior of the concrete topping. They concluded that roughened hollowcore slabs can develop acceptable levels of shear strength with the concrete topping. This paper investigates the properties of the interface between hollowcore slabs with machine cast surface and the concrete topping. Hollowcore slabs from two Ontario manufacturers, A and B, were experimentally tested to evaluate the bond (peel) strength and shear behaviour of the interface between the hollowcore slabs and the cast-in-situ concrete topping. A total of forty eight pull-off tests and eight push-off tests were attempted. Five full scale tests were performed to examine the overall behaviour. This paper gives details about the conducted pull-off, push-off and full scale tests.

\section{TEST SPECIMENS}

The tested hollowcore slabs were received in four shipments from two manufacturers (A and B) located in Ontario, Canada. Table 1 summarizes information about the tested slabs and the conducted tests. Figs. 1 and 2 show their machine cast finish and their cross-sections. The minimum concrete compressive strength was $41 \mathrm{MPa}$ as per manufacturer's specifications. The concrete compressive strength for the full-scale test specimens was evaluated using ASTM C $349^{12}$ using three $50 \mathrm{~mm}$ cubes sampled from the edges of each slab after completing the fullscale tests. The equivalent cylinder concrete compressive strengths are given in Table 2. Number of prestressing strands for each slab is also given in the table.

\section{CONCRETE TOPPING}

Properties of the concrete topping were chosen in accordance with the industry standards. A thickness of $50 \mathrm{~mm}$ was used. The concrete mix contained $10 \mathrm{~mm}$ pea stone aggregates and had 
an average slump of $120 \mathrm{~mm}$. No additives were added to the mix and the specified strength was $25 \mathrm{MPa}$. Before casting the topping, the surface of the hollowcore slabs was submerged with water and then dried to obtain a Saturated Surface Dry (SSD) condition, which prevents the surface from absorbing water from the concrete topping. The area of the concrete topping varied as shown in Table 3 . For the $4^{\text {th }}$ shipment, two concrete areas were cast on each slab to conduct both pull-off and push-off tests. The two areas were separated by utilizing wood forms. Table 3 also presents the average compressive strength of the concrete topping as was determined using ASTM C39 ${ }^{13}$. Wet curing was applied for three days according to clause 7.4.2 of CSA A23.1 ${ }^{14}$. The slabs were also covered with moisture retaining plastic sheets for at least seven days after casting. Temperature of the laboratory was kept constant at $23^{\circ} \mathrm{C}$. Formwork and casting of the concrete topping are illustrated in Fig. 3.

\section{PULL-OFF TESTS}

The concrete topping can be considered fully bonded to the hollowcore slab if the bond strength between the two concrete layers is not less than $0.9 \mathrm{MPa}$ (clause 7.6.4.3.2 of CSA A23.1 ${ }^{14}$ ). This strength can be evaluated in the field using test method 6B of CSA A23.2 ${ }^{15}$. This method involves core drilling of an annular ring into the composite slab and applying a tensile force to the concrete topping. Similar procedure is used in Europe ${ }^{16}$. This section evaluates the surface roughness of the hollowcore slabs and provides details about the conducted pull-off tests.

\subsection{Surface Roughness Evaluation}

The degree of surface roughness varies between hollowcore slabs because of differences in the manufacturing process and/or equipment maintenance. The surface roughness for hollowcore 
slabs with machine cast surface was evaluated using ASTM E965 ${ }^{17}$. This procedure is generally used for pavements and is suitable for surfaces with voids smaller than $25.4 \mathrm{~mm}$, which is the case for the considered surface. Glass beads that pass through sieve No. 60 and are retained on sieve No. 80 are spread over the slab surface in a circular motion using a hard plastic disk. When the beads are flush with the surface, three measurements of the diameter of the resulting circle are taken (Fig. 4). Mean Texture Depth (MTD) is then calculated by dividing the volume of the used beads by the average area of the circle. Results of surface roughness are shown in Table 4 . It is clear that roughness of the machine cast finish is significantly less than the intentional roughness specified by North American design standards. The results also show the high variability of roughness from manufacturer to another and within the same manufacturer.

\subsection{Pull-Off Test Setup}

Pull-off tests were performed according to procedure A of the standard test method $6 \mathrm{~B}$ of CSA A23. $2^{15}$. In this procedure, the tensile strength of the interface between two bonded concrete surfaces is evaluated using a mechanical pullout apparatus that consists of three main components: 1) a pull-off steel disk, which is attached to the concrete topping; 2) a rigid frame to support the hydraulic jack applying the pull-off force and 3) a load cell to record the failure load. This apparatus was manufactured at Western University. The diameter of the used disks was 95 $\mathrm{mm}$, which is slightly smaller than the inner diameter of the bit used for core drilling. Two disk thicknesses were utilized in this project: 1) $100 \mathrm{~mm}$ to ensure a uniform distribution of the tensile force over the interface area as illustrated in Fig. 5(a) and 2) $10 \mathrm{~mm}$ to match the common industry practice. The $100 \mathrm{~mm}$ and $10 \mathrm{~mm}$ disks were used for the $\left(1^{\text {st }}\right.$ and $\left.2^{\text {nd }}\right)$ and the $\left(3^{\text {rd }}\right.$ and $\left.4^{\text {th }}\right)$ shipments, respectively. The disks are shown in Fig. 5. A steel pipe with thickness of $10 \mathrm{~mm}$ 
was used to provide the needed rigid frame. It encompassed the load cell and supported the hydraulic jack. Fig. 6 shows the pull-off apparatus and the general test setup.

\subsection{Pull-Off Test Procedure}

Pull-off tests were initiated by drilling a core through concrete topping that penetrates a minimum of $30 \mathrm{~mm}$ into the hollowcore slab surface as illustrated in Fig. 6. The diameter of the core was $100 \mathrm{~mm}$, matching the current industry practice. Fig. 7(a) shows the core drilling. The steel pull-off disks were bonded to the cores using epoxy compound after roughening the core top surface and the disk bottom surface as shown in Fig. 7(c). The disks were installed on the core using a conventional 5 minute epoxy compound. Fig. 8 shows locations of the cores for the tested slabs. Fig. 9 shows the process of leveling the pull-off disk and attaching the apparatus. Tests were conducted after 24 hours of the epoxy application. The load cell was first attached to the pull-off disk using a threaded rod. The rate of loading was approximately $80 \mathrm{~N} / \mathrm{s}$, which is within the $(50$ to $100 \mathrm{~N} / \mathrm{s})$ range specified in clause 5.1 .4 of CSA A23.2-6B ${ }^{15}$. It was controlled by monitoring the digital load meter while increasing the tensile load using a manual hydraulic pump.

\subsection{Results and Discussion}

The maximum load prior to failure was retrieved from the digital load meter and recorded for each pull-off test. The weights of the steel disk, load cell, threaded rods and the hydraulic jack were deducted from the maximum load. The load was then divided by the cross sectional area of the core to obtain the bond strength at failure. The bond strength and the type of failure associated with each core are summarized in Table 5. Fig. 10 shows the different types of failure 
observed during the pull-off tests. Results of 13 tests from manufacturer A and 14 tests from manufacturer B were below the $0.9 \mathrm{MPa}$ limit. Slabs of $4^{\text {th }}$ shipment showed poor performance (24 tests). Four of the specimens failed at the interface and did not provide any tensile resistance. Two slabs, PSMA4-2 and PSMB4-2, provided unacceptable bond strength. This can be attributed to the considerably low surface roughness for this shipment. The slabs from the other shipments showed acceptable performance except for core C1 of slab FMA2-2 and cores C1 and C2 of slab FMB2-2. This is likely because of a localized surface condition of the slab surface prior to casting of the topping. The bond between the concrete topping and the hollowcore slab surface is controlled by two mechanisms: chemical bond and mechanical bond. The later is dependent on the surface roughness. The chemical bond is affected by the moisture content of the hollowcore slab surface, which was optimized utilizing the SSD moisture condition ${ }^{13}$. Fig. 11 shows the pull-off test results in terms of surface roughness, where it can be observed that slabs with surface roughness higher than $0.30 \mathrm{~mm}$ achieved acceptable bond strength.

\section{PUSH-OFF TESTS}

The push-off tests were conducted in a vertical orientation to permit easier alignment of the MTS hydraulic actuator with the existing vertical support frame at the structures lab at Western University. Fig. 12 shows a hollowcore slab installed in the vertical direction with its concrete topping resting on a $50 \mathrm{~mm}$ thick steel plate. When a vertical force is applied using the shown MTS hydraulic actuator, a spreader steel beam distributes the force on the hollowcore slab. The steel plate then reacts with a force on the concrete topping. This force generates shear and peel stresses along the interface between the slab and the topping. 
A steel frame, positioned behind the hollowcore slab, prevents the lateral movement. The soffit side of the hollowcore slab is sufficiently smooth, which allows free movement of the slab relative to the steel frame. $50 \mathrm{~mm}$ wide by $3 \mathrm{~mm}$ thick Korolath bearing pads are used under the steel spreader beam and between the steel plate and the concrete topping to guarantee a uniform stress distribution at those locations. The tests were conducted by applying the load using the MTS actuator at a rate of $10 \mathrm{kN}$ per minute.

To capture the state of strains in the concrete topping, five strain gauges were attached to its top surface as illustrated in Fig. 13. Strain gauges S1, S3, and S5 measured the strains in the direction of the applied load and strain gauges S2 and S4 measured the distribution of stresses across the topping width. The push-off test induced two types of stresses on the interface between the concrete topping and the hollowcore slab: (1) shear stresses (stresses parallel to the interface) and (2) peel stresses (stresses perpendicular to the interface).

Movement in the shear and peel directions were recorded using four Linear Variable Displacement Transducers (LVDTs), L1 to L4, as shown in Fig. 13. LVDTs L1 and L2 measured the peel deformations and LVDTs L3 and L4 measured the shear deformations between the hollowcore slab and the concrete topping.

\subsection{Test Results and Discussion}

The push-off tests were conducted on slabs of the $1^{\text {st }}$ and the $4^{\text {th }}$ shipments. Slabs PSMA4-1, PSMB4-1, PSMB4-2 and PSMB4-3 achieved zero shear strength, which is directly related to their low surface roughness.

The average horizontal shear strength $v_{h}$ avg. can be obtained from the push-off tests using Eq. (1), where $P_{u}$ is the ultimate applied load, at which the concrete topping is separated from the 
hollowcore slab, and $A$ is the interface area. Values of $P_{u}$ and the corresponding slip and peel deformations and $v_{h}$ avg. are shown in Table 6.

$$
v_{\text {h avg. }}=\frac{P_{u}}{A}
$$

Three slabs achieved average shear strength higher than $0.70 \mathrm{MPa}$ and $0.55 \mathrm{MPa}$ limits that are required by CSA A23.3 ${ }^{1}$ and ACI $318^{2}$, respectively. However, one slab did not achieve the required limit, PSMA4-3 mainly because of its low surface roughness $(0.152 \mathrm{~mm})$. Strains recorded by strain gauges S2, S3 and S4 exhibited close agreement in measured values and trends as illustrated in Fig. 14. The difference in the strain gauge readings is a result of two factors: (1) rotational misalignment between the strain gauge axis and the loading axis and (2) slight inclination of the concrete topping bottom surface. However, considering the consistent trend for all strain readings and the relatively small strain difference of $0.0005 \mathrm{~mm} / \mathrm{mm}$, the difference was deemed not to have affected the general behaviour of the test.

The concrete strain readings from strain gauges S1, S3 and S5 are shown in Fig. 15 for slab SMA1-2. Strain gauge S5 initially recorded the highest readings. At a load level of about 200 $\mathrm{kN}$, strains measured by S3 started to increase at a high rate indicating a fracture in the zone of S5. At load level of about $320 \mathrm{kN}$, readings from strain gauge S1 started to pick up. This mechanism illustrates a progressive type of failure, which is initiated by the fracture of the interface between the hollowcore slab and concrete topping at the loading end.

Readings of the strain gauges gave evidence of load redistribution within the slab surface. However, extremely brittle and abrupt failure was observed because of the small recorded slips. The average slips at failure were calculated using readings of LVDTs L3 and L4 and are shown in Table 6. The load versus slip curves are shown in Fig. 16(a). The peel deformations recorded by LVDT L2 are shown in Fig. 16(b). LVDT L1 did not return any measurable readings. 
The shear force is resisted at the interface by two mechanisms, bond and friction. The shear and peel stiffnesses reduce when the bond between the hollowcore slab and the topping is lost. This is apparent in the slip and peel graphs of specimen SMA1-2, where the slip and peel deformations did not initiate until load level of about $50 \mathrm{kN}$ at which the stiffness has decreased due to the loss of the interfacial bond. After that load level, mechanical bond (shear-friction) is responsible for transferring the shear stresses. For slab PSMA4-2, initial bond loss is noticed from the peel deformations at load level of about $50 \mathrm{kN}$, however the slip did not start until load level of $100 \mathrm{kN}$ indicating that bond loss was gradual along the interface. Slab PSMA4-3 achieved the lowest strength, which is directly attributed to its low surface roughness.

\section{FULL-SCALE TESTS}

The full-scale tests were conducted using three-point bending as shown in Fig. 17. The total length of each slab was $3658 \mathrm{~mm}$. Both slabs from manufacturer A, FMA2-1 and FMA2-2 were 254 mm deep. Slabs FMB2-1 and FMB2-2 had a thickness of $254 \mathrm{~mm}$ and slab FMB2-3 was 304 $\mathrm{mm}$ deep. The distance between the support and the point load was $1329 \mathrm{~mm}$ resulting in shear span ratios of 4.37 and 5.25 for the $304 \mathrm{~mm}$ and $254 \mathrm{~mm}$ slabs, respectively.

The contact surface was reduced for slabs FMA2-2 and FMB2-1 by inducing a separation in the concrete topping. This discontinuity in the concrete topping was achieved by saw cutting as illustrated in Fig. 18. The saw cut created a $4 \mathrm{~mm}$ separation gap in the concrete topping. The three specimens that did not have a gap in their topping were instrumented with six LVDTs as shown in Fig. 19(a). Two LVDTs (LE and LW) located at mid-span of the slabs measured the vertical deflection. Four LVDTs measured the slip between the concrete topping and the hollowcore slab at the middle of the shear span (SLE1 and SLW1) and near the supports (SLE2 
and SLW2). Four strain gauges were also attached to the sides of the concrete topping and the hollowcore slab at the mid-span section. They were installed at a distance of $10 \pm 5 \mathrm{~mm}$ from the interface line. The distance varied depending on the adequacy of the concrete surface.

Instrumentation layout of slabs FMA2-2 and FMB2-1 is illustrated in Fig. 19(b). Two LVDTs (LE and LW) located at mid-span of the slabs measured the vertical deflection. The slip and peel deformations between the hollowcore slabs and the topping were measured using LVDTs (SLCE and SLCW) and (PCE and PCW), respectively. Four strain gauges at the midspan section were also used to monitor concrete strains. A static loading rate of $10 \mathrm{kN}$ per minute was applied for all tests to accurately capture the behaviour and failure mechanism. The instrumentation data was collected through a data acquisition system every second.

\subsection{Test Results}

The load-deflection graphs are shown in Fig. 20 with the deflection values calculated based on the average of LVDTs LW and LE. The load-deflection curves demonstrate typical flexural behaviour. The initial change in the load-deflection slope was caused by cracking when the tensile stress at the bottom of the hollowcore slab exceeds the cracking stress. Yielding caused additional changes in slope of the load-deflection curve. Three of the tested slabs failed in flexural shear mode, where a flexural crack had initiated and then propagated triggering shear failure. Two slabs have failed by strands rupture, FMA2-1 and FMA2-2. Fig. 21 shows the failure modes for all slabs.

Table 7 summarizes the experimental failure loads along with the predicted failure loads for untopped and topped slabs. The predicted failure loads are given for both flexural and shear failures. The flexural values were estimated by assuming a compressive strain of $0.0035^{1}$ either 
at the top of the hollowcore slab or at the top of the composite section. The strand strain was then obtained based on equilibrium. The shear values are based on the general method of CSA A23.3 ${ }^{1}$. The shear capacity ranges between two values as shown in Table 7 where the higher value represents the shear capacity close to the support (zero moment) and the lower value is the capacity close to the applied load (maximum moment). The slabs that failed in flexure-shear fit will within those capacity ranges. Slip and peel measurements obtained from the displacement LVDTs are illustrated in Fig. 22. Negative LVDT readings indicate that the LVDT has expanded, which means that a slip or peel has occurred. Positive values indicate that the LVDT has compressed, which results from the curvature of the slab specimen due to bending under loading. Table 8 presents the maximum slip and peel deformations for all of the tested slabs.

The slip measured for slabs FMA2-1 and FMB2-3 was almost zero suggesting that full composite action was achieved. Specimen FMA2-2 had better ductility than FMA2-1. This ductility resulted from the observed slip in this specimen. Specimen FMB2-2 had slip values that are higher than FMA2-1 and FMB2-3 because of its low bond strength (average of $0.80 \mathrm{MPa}$ with one of the cores having zero bond strength). However, these slip values were very small and did not affect the overall performance of the specimen. Slab FMB2-3 had a thickness of $304 \mathrm{~mm}$ including the concrete topping, which is greater than the thickness of slab FMB2-2 but had similar prestressing reinforcement. Horizontal shear failure was not observed for slab FMB2-3 and the slab acted compositely up to failure. This indicates that the increased thickness did not seem to have affected the horizontal shear behaviour.

Careful inspection of the slip and peel curves for the two slabs that had gaps in their topping illustrated consistency between peel and slip readings. The slip values for specimen FMA2-2 show an initial high horizontal shear stiffness that is significantly reduced at a load of about 186 
$\mathrm{kN}$. This might be due to loss of the bond resistance at the interface. The slippage measured at the west side was higher than that measured at the east side. This is clearly linked to the peel deformations that show higher values at the west side than the east side. Same observations can be made about slab FMB2-1. Strain readings for slab FMB2-1 are shown in Fig. 23. Near failure, bond between the concrete topping and the hollowcore slabs was weakened, which triggered slip along the interface and caused the compressive stresses in the concrete topping to unload and the tensile strains in the top of the hollowcore slab to unload and change to compressive strains.

The average horizontal shear stress at failure, $v_{h \text {-test, was }}$ calculated using the two methods available in the design standards. The first method utilizes the maximum shear force to represent the maximum horizontal shear force for design, clause 17.5.3 of ACI $318^{2}$ and clause 17.4.3 of CSA A23.3 ${ }^{1}$. The maximum horizontal shear stress is then calculated by dividing the maximum shear force by $\left(b_{v} d\right)$, where $b_{v}$ is the width of the interface between the topping and the hollowcore slab and $d$ is the depth of the composite section. The second method follows the maximum moment section procedure outlined in clause 17.4.4 of A23.3 ${ }^{1}$ and clause 17.5.4 of ACI $318^{2}$. Table 9 shows the calculated shear stress at failure for each tested slabs.

The minimum acceptable horizontal shear strength for composite hollowcore slabs as specified in the North American standards A23.3 $3^{1}$ and ACI $318^{2}$ are $0.70 \mathrm{MPa}$ and $0.55 \mathrm{MPa}$, respectively. Considering the cut-slabs FMA2-2 and FMB2-1, the $1^{\text {st }}$ Method is not applicable because it does not account for the reduction in the interface length, thus its results were not shown in Table 9. The $2^{\text {nd }}$ Method is based on full bond between the hollowcore slab and the concrete up to failure, which is not consistent with the observations of the cut-slabs tests. The load carrying capacity of slab FMA2-1 was less than the other slabs because it did not contain comparable prestressing reinforcement. This reduction caused the slab to fail before generating enough horizontal shear 
stress to the limits that can be compared with the North American standards. The rest of the slabs, FMB2-2 and FMB2-3 achieved comparable or higher than the limits stated in the North American standards. In view of these results and considering that all of the tested slabs achieved full composite capacity, it can be concluded that the used surface roughness is sufficient to produce adequate composite action.

\section{CONCLUSIONS}

This paper examined the peel and shear behaviour of the interface between hollowcore slabs with machine cast surface and concrete topping through pull-off, push-off and full-scale tests. The work conducted in this study is distinguished from previous work by adapting a comprehensive experimental program, which gave broader understanding of the performance of composite hollowcore slabs. It also provides hollowcore slab manufacturers with a testing methodology to ensure adequate composite action. In view of the presented results and discussions, the following conclusions can be drawn:

Surface Roughness and bond strength between hollowcore slabs and topping concrete:

- The surface roughness provided by the machine cast finish is much lower than the intentional roughness required by North American design standards.

- High variability of surface roughness was observed for different shipments from the same manufacturer.

- Based on the results of the Pull-off tests, the bond strength between hollowcore slabs with machine cast finish and the concrete topping is expected to satisfy the $0.9 \mathrm{MPa}$ limit in A23.2 $2^{15}$ if the machine cast surface roughness exceeds $0.3 \mathrm{~mm}$. This threshold is valid for the slabs produced by the participating manufacturers. 
Shear strength between hollowcore slabs and topping concrete:

- Push-off test results indicated that if the surface roughness of hollowcore slabs is acceptable $(>0.3 \mathrm{~mm})$ and the slab is free from contamination, the shear strength of the interface layer between the slab and the concrete topping is higher than the minimum acceptable shear stresses specified in North American design standards.

- The shear strength was found to vary significantly from manufacturer to another.

\section{Full-scale tests:}

- Full-scale three point bending tests have shown that hollowcore slabs with machine cast finish and acceptable roughness can provide adequate composite strength up to ultimate condition. Thus, the horizontal shear strength required by CSA A23.3 $3^{1}$ and ACI $318^{2}$ can be met without the need for surface roughening.

- Two of the slabs had a gap in their concrete topping limiting the effective area of the topping to a small area in the middle of the slab. The topping of the two slabs experienced slip and peel deformations that did not affect the overall behaviour. This might be due to the confining action provided by the load that acts on the topping. This suggests that the live loads might increase the shear strength provided by the interface layer. Additional research is needed to clarify this point.

\section{ACKNOWLEDGMENTS}

The authors would like to acknowledge the enthusiastic guidance and technical support provided by Mr. Anil Mehta from The Prestressed Group (Windsor, ON). Appreciation is extended to the 
Canadian Precast/Prestressed Institute (CPCI) and the Ontario Centers of Excellence (OCE) for their financial support.

\section{REFERENCES}

1. CSA A23.3, 2004, "Design of concrete structures", Canadian Standard Association (CSA), Mississauga, ON, Canada.

2. ACI 318, 2008, "Building Code Requirements for Structural Concrete (ACI 318-08) and Commentary", American Concrete Institute, Michigan, United States.

3. Ozell, A.M., Cochran J.W., 1956, "Behaviour of Composite Lintel Beams in Bending", PCI Journal, V. 1, No. 1, pp. 38-48.

4. Hanson, N.W., 1960, "Horizontal Shear connections", Journal of the Research and Development Laboratories, Portland Cement Association, V. 2, No. 2, pp. 38-58.

5. TB74-B6, 1974, "Composite Systems Without roughness", Technical Bulletin, Concrete Technology Association (CTA), CTA 35, pp 271-316.

6. TB76-B4, 1976, "Composite Systems without Ties", Technical Bulletin, Concrete Technology Association (CTA), CTA 36, pp 317-360.

7. Girhammar, U.A. and Pajari, M., 2008, "Tests and analysis on shear strength of composite slabs of hollow core units and concrete topping”, Construction and Building Materials, 22, $1708-1722$.

8. Mones, R.M. and Breña S.F., "Hollow-core slabs with cast-in-place toppings: A study of interfacial shear strength”, PCI Journal, v 58, n 3, p 124-141, summer 2013. 
9. Ibrahim, I.S., Elliott, K.S., Copeland, S., 2006, "Interface Shear Stress of Hollow Core with Concrete Toppings", $\sigma^{\text {th }}$ International Conference on Concrete Engineering and Technology (CONCET). Kuala Lumpur: Institution of Engineers Malaysia.

10. Ibrahim, I.S., Elliott, K.S. and Copeland, S., 2008. "Bending Capacity of Precast Prestressed Hollow Core Slabs with Concrete Toppings." Malaysian Journal of Civil Engineeing. 20(2): $260-283$.

11. Adawi A., Youssef M.A., Meshaly M.E., in-press, “Analytical Modeling of the Interface between Lightly Roughened Hollowcore Slabs and Cast-In-Place Concrete Topping”, ASCE Journal of Structural Engineering, accepted March 2014.

12. ASTM C349, 2008, "Standard Test Method for Compressive Strength of Hydraulic-Cement Mortars (Using Portions of Prisms Broken in Flexure), ASTM International, Pennsylvania, United States.

13. ASTM C39, 2005, "Standard Test Method For Compressive Strength of Cylindrical Concrete Specimens", ASTM International, Pennsylvania, United States.

14. CSA A23.1, 2009, "Concrete materials and methods of concrete construction", Canadian Standard Association (CSA), Mississauga, ON, Canada.

15. CSA A23.2, 2009, “Test methods and standard practices for concrete”, Canadian Standard Association (CSA), Mississauga, Canada.

16. FIP Commission on Prefabrication, 1982, "Shear at the interface of precast and in situ concrete", Guide to Good Practice, Sweden.

17. ASTM E965, 2006, "Standard Test Method for Measuring Pavement Macrostructure Depth Using a Volumetric Technique”, ASTM International, Pennsylvania, United States. 
Table 1: Hollowcore slab specimens

\begin{tabular}{|c|c|c|c|c|}
\hline Shipment & Manufacturer & Slab Label & Tests & $\begin{array}{l}\text { Size, } \mathbf{m m} \\
(\mathbf{L}, \mathbf{W}, \mathbf{D})^{*}\end{array}$ \\
\hline \multirow{2}{*}{$\begin{array}{l}\text { Shipment } \\
\quad \# 1\end{array}$} & \multirow[t]{2}{*}{ A } & PMA1-1, PMA1-2 & 6 Pull-off & $\begin{array}{l}1220,1220, \\
203\end{array}$ \\
\hline & & SMA1-1, SMA1-2 & 2 Push-off & $\begin{array}{l}1220,1220, \\
203\end{array}$ \\
\hline \multirow{3}{*}{$\begin{array}{l}\text { Shipment } \\
\quad \# 2\end{array}$} & A & FMA2-1, FMA2-2 & $\begin{array}{l}6 \text { Pull-off, } \\
2 \text { Full-scale }\end{array}$ & $\begin{array}{l}3658,1220, \\
203\end{array}$ \\
\hline & \multirow[t]{2}{*}{ B } & FMB2-1, FMB2-2 & $\begin{array}{l}6 \text { Pull-off, } \\
2 \text { Full-scale }\end{array}$ & $\begin{array}{l}3658,1220, \\
203\end{array}$ \\
\hline & & FMB2-3 & $\begin{array}{l}3 \text { Pull-off, } \\
1 \text { Full-scale }\end{array}$ & $\begin{array}{l}3658,1220, \\
254\end{array}$ \\
\hline $\begin{array}{l}\text { Shipment } \\
\# 3 \\
\end{array}$ & A & FMA3-1 & 3 Pull-off & $\begin{array}{l}3658,1220, \\
254\end{array}$ \\
\hline \multirow{2}{*}{$\begin{array}{l}\text { Shipment } \\
\quad \# 4\end{array}$} & $\bar{A}$ & $\begin{array}{l}\text { PSMA4-1, PSMA4-2, } \\
\text { PSMA4-3 }\end{array}$ & $\begin{array}{l}12 \text { Pull-off, } \\
3 \text { Push-off }\end{array}$ & $\begin{array}{l}1220,1220, \\
203\end{array}$ \\
\hline & B & $\begin{array}{l}\text { PSMB4-1, PSMB4-2, } \\
\text { PSMB4-3 }\end{array}$ & $\begin{array}{l}12 \text { Pull-off, } \\
3 \text { Push-off }\end{array}$ & $\begin{array}{l}1220,1220, \\
203\end{array}$ \\
\hline
\end{tabular}

* L: Length of slab, W: Width of slab, D: Depth of slab

Table 2: Information for the full-scale slabs

\begin{tabular}{|l|c|c|c|}
\hline \multirow{2}{*}{$\begin{array}{l}\text { Slab } \\
\text { Label }\end{array}$} & \multicolumn{2}{|c|}{$\begin{array}{c}\text { Average Concrete Compressive Strength } \\
\boldsymbol{f}_{\boldsymbol{c}}^{\prime} \text { (MPa) }\end{array}$} & \multirow{2}{*}{ Strand Pattern } \\
\cline { 2 - 4 } & Average Value & Standard Deviation & \\
\hline FMA2-1 & 53 & 2.9 & $4-\frac{1^{\prime \prime}}{2}$ strands \\
\hline FMA2-2 & 50 & 3.1 & $4-\frac{1}{2}^{\prime \prime}$ strands \\
\hline FMB2-1 & 62 & 4.1 & $7-\frac{1^{\prime \prime}}{2}$ strands \\
\hline FMB2-2 & 58 & 3.8 & $7-\frac{1}{2}$ strands \\
\hline FMB2-3 & 60 & & $7-\frac{1}{2}$ strands \\
\hline
\end{tabular}


Table 3: Concrete topping

\begin{tabular}{|l|l|l|c|}
\hline \multicolumn{1}{|c|}{ Slab Label } & \multicolumn{1}{|c|}{ Tests } & \multicolumn{1}{|c|}{$\begin{array}{c}\mathbf{L}^{*}, \mathbf{W}^{*}, \mathbf{T}^{*} \\
\mathbf{m m}\end{array}$} & $\begin{array}{c}\text { Average Concrete } \\
\text { Compressive Strength } \\
\text { (STD*) MPa }\end{array}$ \\
\hline PMA1-1, PMA1-2 & Pull-off & $1220,1220,50$ & $32(1.6)$ \\
\hline SMA1-1, SMA1-2 & Push-off & $508,508,50$ & $32(1.6)$ \\
\hline FMA2-1, FMA2-2 & Pull-off, Full-scale & $3658,1220,50$ & $30(1.2)$ \\
\hline FMB2-1, FMB2-2, FMB2-3 & Pull-off, Full-scale & $3658,1220,50$ & $30(1.2)$ \\
\hline FMA3-1 & Pull-off & $1000,500,50$ & $33(0.8)$ \\
\hline PSMA4-1, PSMA4-2, PSMA4-3 & $\begin{array}{l}\text { Pull-off } \\
\text { Push-off }\end{array}$ & $\begin{array}{l}1000,500,50 \\
508,508,50\end{array}$ \\
\hline PSMB4-1, PSMB4-2, PSMB4-3 & $\begin{array}{l}\text { Pull-off } \\
\text { Push-off }\end{array}$ & $\begin{array}{l}1000,500,50 \\
508,508,50\end{array}$ \\
\hline
\end{tabular}

*L: length, W: width, T: thickness, STD: standard deviation

Table 4: Surface roughness evaluation results

\begin{tabular}{|l|c|c|}
\hline \multicolumn{1}{|c|}{ Slab Label } & Surface Roughness (mm) & Average Roughness (mm) \\
\hline PMA1-1 & 0.341 & \\
PMA1-2 & 0.360 & 0.353 \\
SMA1-1 & 0.351 & \\
SMA1-2 & 0.361 & 0.320 \\
\hline FMA2-1 & 0.325 & \\
FMA2-2 & 0.314 & 0.311 \\
\hline FMB2-1 & 0.320 & 0.314 \\
FMB2-2 & 0.297 & 0.165 \\
FMB2-3 & 0.315 & \\
\hline FMA3-1 & 0.314 & \\
\hline PSMA4-1 & 0.140 & 0.106 \\
PSMA4-2 & 0.202 & \\
PSMA4-3 & 0.152 & \\
\hline PSMB4-1 & 0.105 & \\
PSMB4-2 & 0.121 & \\
PSMB4-3 & 0.093 & \\
\hline
\end{tabular}


Table 5: Pull-off test results

\begin{tabular}{|c|c|c|c|c|c|}
\hline \multirow{2}{*}{$\begin{array}{c}\text { Slab } \\
\text { Label }\end{array}$} & \multicolumn{2}{|l|}{ Core Bond Strength, MPa / Failure Type } & \multicolumn{2}{c|}{$\begin{array}{c}\text { Average Bond } \\
\text { Strength, MPa }\end{array}$} \\
\cline { 2 - 5 } & C1 & C2 & C3 & C4 & \\
\hline PMA1-1 & $1.51 / \mathrm{I}$ & $1.78 / \mathrm{I}$ & $2.63 / \mathrm{I}$ & -- & 1.97 \\
\hline PMA1-2 & $3.91 / \mathrm{H}$ & $3.06 / \mathrm{H}$ & $2.81 / \mathrm{H}$ & -- & 3.26 \\
\hline FMA2-1 & $1.71 / \mathrm{I}$ & $1.18 / \mathrm{I}$ & $1.99 / \mathrm{X}$ & -- & 1.63 \\
\hline FMA2-2 & $\underline{0.44 / \mathrm{I}}$ & $1.14 / \mathrm{X}$ & $1.96 / \mathrm{T}$ & -- & 1.18 \\
\hline FMB2-1 & $2.19 / \mathrm{I}$ & $2.57 / \mathrm{I}$ & $1.23 / \mathrm{I}$ & -- & 2.00 \\
\hline FMB2-2 & $\underline{0.00 / \mathrm{D}}$ & $\underline{0.77 / \mathrm{I}}$ & $1.70 / \mathrm{I}$ & -- & $\underline{0.80}$ \\
\hline FMB2-3 & $2.31 / \mathrm{X}$ & $2.48 / \mathrm{X}$ & $1.87 / \mathrm{H}$ & -- & 2.22 \\
\hline FMA3-1 & $1.52 / \mathrm{X}$ & $1.34 / \mathrm{X}$ & $1.44 / \mathrm{I}$ & -- & 1.43 \\
\hline PSMA4-1 & $\underline{0.00 / \mathrm{I}}$ & $\underline{0.00 / \mathrm{I}}$ & $\underline{0.00 / \mathrm{I}}$ & $\underline{0.00 / \mathrm{I}}$ & $\underline{0.00}$ \\
\hline PSMA4-2 & $\underline{0.58 / \mathrm{X}}$ & $\underline{0.78 / \mathrm{I}}$ & $\underline{0.60 / \mathrm{X}}$ & $\underline{0.76 / \mathrm{I}}$ & $\underline{0.68}$ \\
\hline PSMA4-3 & $\underline{0.00 / \mathrm{I}}$ & $\underline{0.00 / \mathrm{I}}$ & $\underline{0.00 / \mathrm{I}}$ & $\underline{0.00 / \mathrm{I}}$ & $\underline{0.00}$ \\
\hline PSMB4-1 & $\underline{0.00 / \mathrm{I}}$ & $\underline{0.00 / \mathrm{I}}$ & $\underline{0.00 / \mathrm{I}}$ & $\underline{0.00 / \mathrm{I}}$ & $\underline{0.00}$ \\
\hline PSMB4-2 & $\underline{0.00 / \mathrm{I}}$ & $\underline{0.00 / \mathrm{I}}$ & $\underline{0.51 / \mathrm{I}}$ & $\underline{0.61 / \mathrm{X}}$ & $\underline{0.56}$ \\
\hline PSMB4-3 & $\underline{0.00 / \mathrm{I}}$ & $\underline{0.00 / \mathrm{I}}$ & $\underline{0.00 / \mathrm{I}}$ & $\underline{0.00 / \mathrm{I}}$ & $\underline{0.00}$ \\
\hline
\end{tabular}

$\mathrm{H}$ (hollowcore failure): failure occurred in the hollowcore slab layer,

I (interface failure): failure occurred at the interface layer,

$\mathrm{T}$ (topping failure): failure occurred in the concrete topping layer,

$\mathrm{X}$ (epoxy failure): the pull-off disk separated from the concrete topping.

Note: underlined values indicate bond strength less than $0.90 \mathrm{MPa}$ required by A23.2 ${ }^{15}$-6B. 
Table 6: Push-off test results

\begin{tabular}{|c|c|c|c|c|}
\hline Slab & $\boldsymbol{P}_{\boldsymbol{u}}(\mathbf{k N})$ & Slip $(\mathbf{m m})$ & Peel (mm) & $\boldsymbol{v}_{\boldsymbol{h} \text { avg. }}(\mathbf{M P a})$ \\
\hline SMA1-1 & 510 & - & - & 1.98 \\
\hline SMA1-2 & 359 & 0.606 & 0.404 & 1.39 \\
\hline PSMA4-2 & 308 & 0.851 & 0.851 & 1.19 \\
\hline PSMA4-3 & 66.0 & 0.980 & 0.017 & 0.256 \\
\hline
\end{tabular}

Table 7: Predicted capacity of the tested slabs (full-scale tests)

\begin{tabular}{|l|c|c|c|c|c|}
\hline Slab & \multirow{2}{*}{$\begin{array}{c}\text { Experimental } \\
\text { Failure Load } \\
\text { P (kN) }\end{array}$} & \multicolumn{3}{|c|}{ Predicted Capacity in terms of Load P, kN } \\
\cline { 3 - 6 } & & Shear Failure & \multicolumn{2}{c|}{ Flexural Failure } \\
\cline { 3 - 6 } & & Topped & untopped & topped & untopped \\
\hline FMA2-1 & 253 & $270-544$ & $205-444$ & 262 & 206 \\
\hline FMA2-2 & 244 & $267-536$ & $199-434$ & 260 & 204 \\
\hline FMB2-1 & 380 & $288-630$ & $535-222$ & 383 & 315 \\
\hline FMB2-2 & 410 & $281-619$ & $215-512$ & 382 & 312 \\
\hline FMB2-3 & 512 & $336-694$ & $256-571$ & 494 & 428 \\
\hline
\end{tabular}

Table 8: Full-scale test results at failure loads

\begin{tabular}{|l|c|c|c|c|c|}
\hline \multirow{2}{*}{$\begin{array}{l}\text { Specimen } \\
\text { Label }\end{array}$} & $\begin{array}{c}\text { Max. Load } \\
\mathbf{P}, \mathbf{k N}\end{array}$ & \multicolumn{2}{|c|}{ Max. Slip $\delta \boldsymbol{s , ~ m m}$} & \multicolumn{2}{|c|}{ Max. Peel $\delta \boldsymbol{p}, \mathbf{m m}$} \\
\cline { 3 - 6 } & & $\mathbf{E}$ & $\mathbf{W}$ & $\mathbf{E}$ & $\mathbf{W}$ \\
\hline FMA2-1 & 253 & 0.000 & 0.004 & ------ & ---- \\
\hline FMA2-2 & 244 & 1.949 & 3.279 & 0.315 & 1.643 \\
\hline FMB2-1 & 380 & 1.263 & 3.018 & 2.030 & 0.817 \\
\hline FMB2-2 & 410 & 0.270 & 0.165 & ----- & ----- \\
\hline FMB2-3 & 512 & 0.021 & 0.000 & ----- & ----- \\
\hline
\end{tabular}


Table 9: horizontal shear strength results

\begin{tabular}{|l|c|c|c|}
\hline \multirow{2}{*}{ Labecimen } & Failure & \multicolumn{2}{|c|}{ Horizontal Shear Stress $v_{\text {h-test }}$ MPa } \\
\cline { 3 - 4 } & \multirow{2}{*}{ Load P, kN } & $1^{\text {st }}$ Method (Max. Shear Force) & $2^{\text {nd }}$ Method (Max. Moment Section) \\
\hline FMA2-1 & 253 & 0.409 & 0.471 \\
\hline FMA2-2 & 244 & --- & 1.04 \\
\hline FMB2-1 & 380 & --- & 1.77 \\
\hline FMB2-2 & 410 & 0.662 & 0.799 \\
\hline FMB2-3 & 512 & 0.734 & 0.802 \\
\hline
\end{tabular}




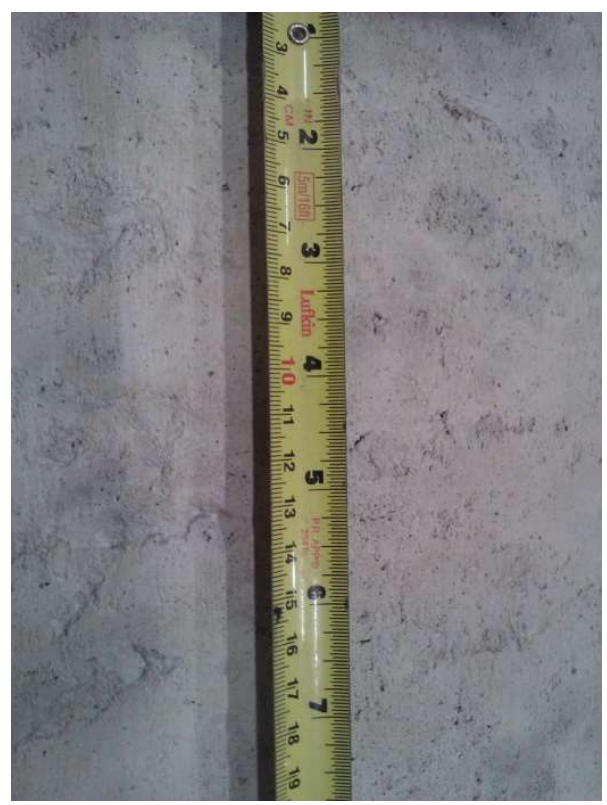

Fig. 1: Typical machine cast finish.
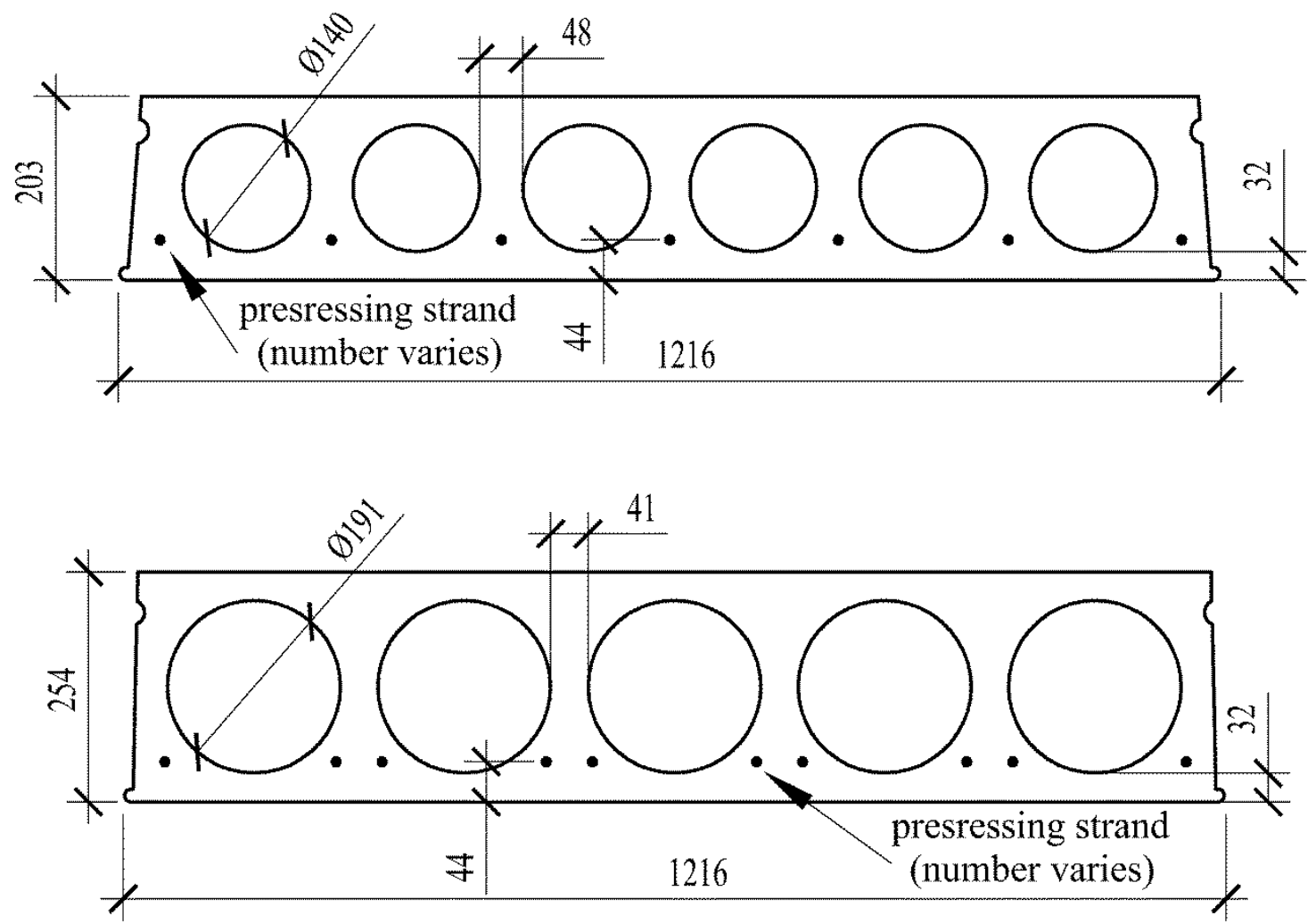

Fig. 2: Cross-sections of the tested hollowcore slabs (all dimensions are in $\mathrm{mm}$ ). 


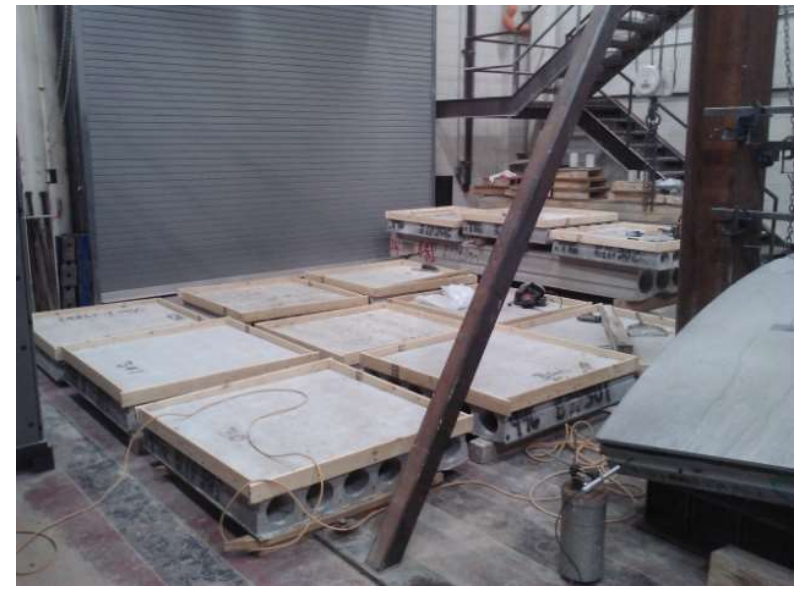

(a) Before casting the topping.

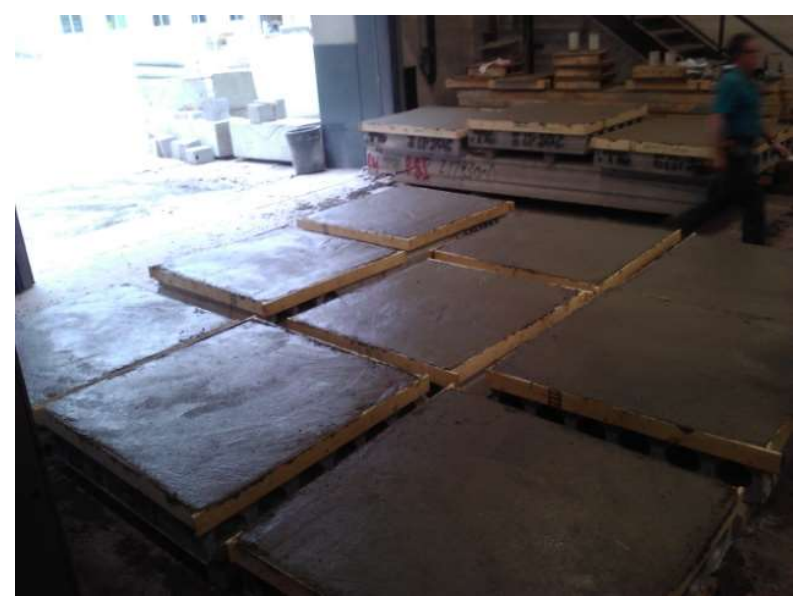

(c) After casting the topping ( $1^{\text {st }}$ shipment).

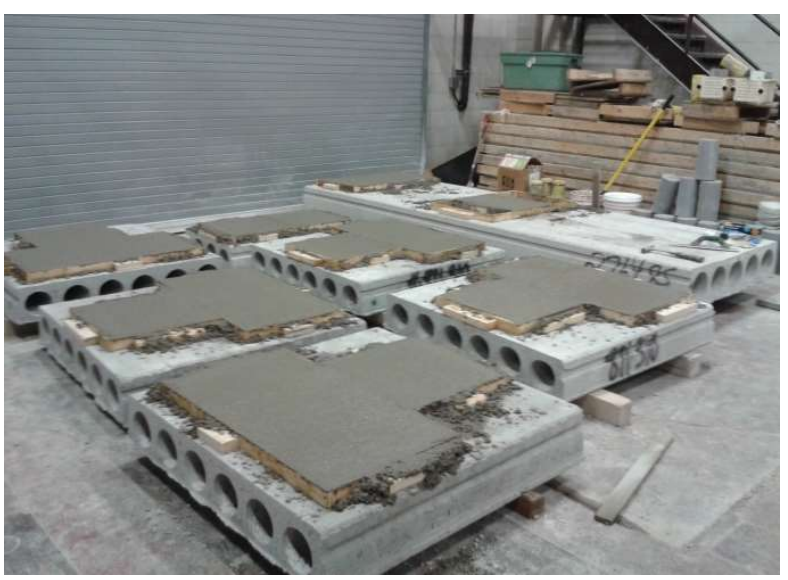

(e) After casting the topping ( $4^{\text {th }}$ shipment).

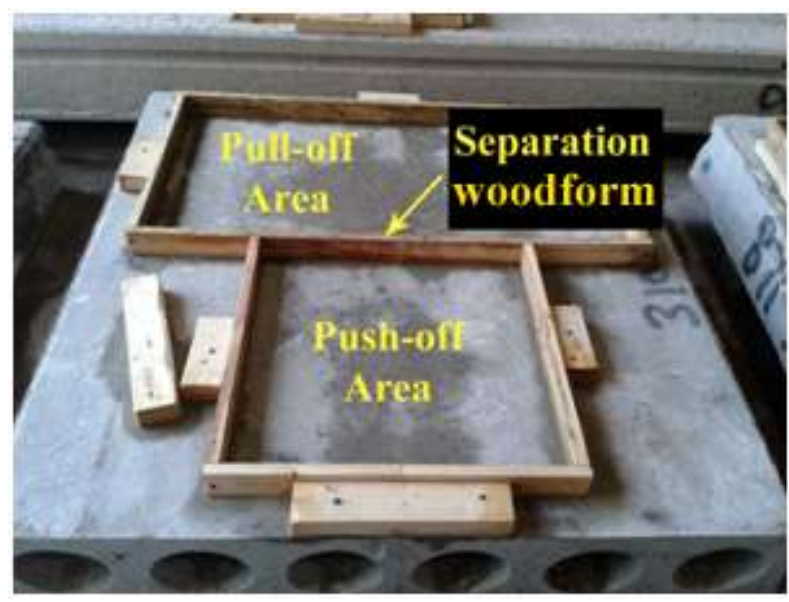

(b) Before casting ( $4^{\text {th }}$ shipment).

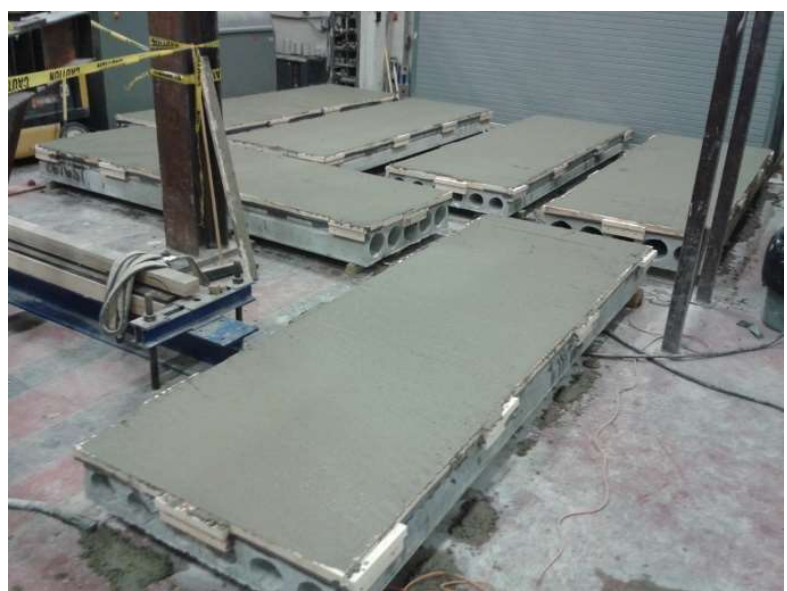

(d) After casting the topping ( $2^{\text {nd }}$ shipment).

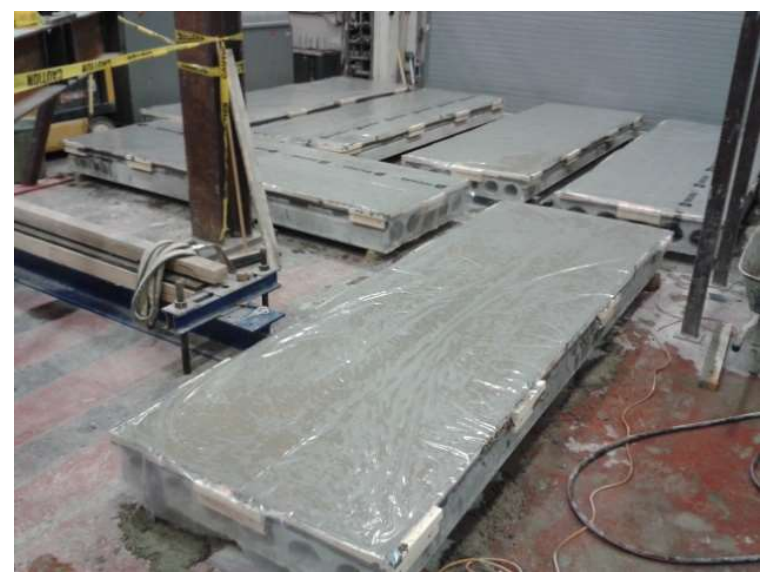

(f) Curing of the concrete topping.

Fig. 3: Formwork and casting of the concrete topping. 


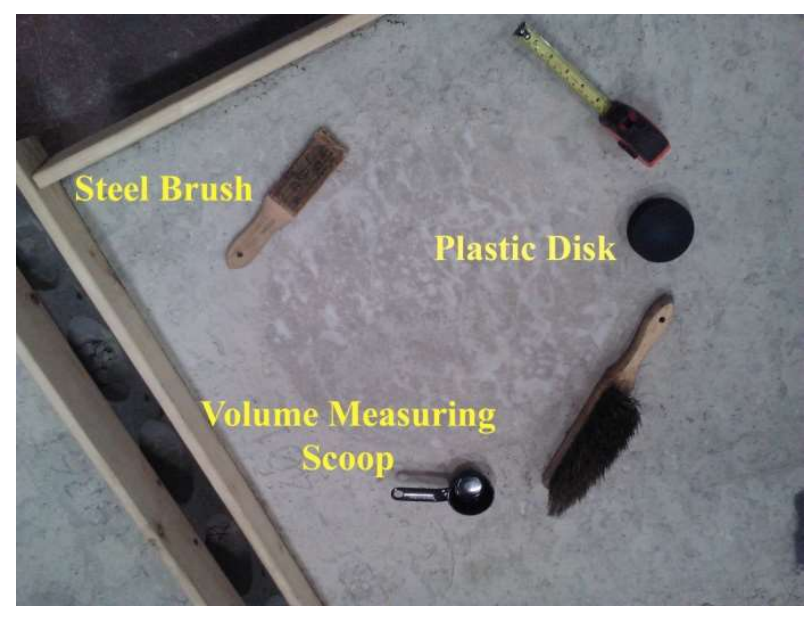

(a) Tools.

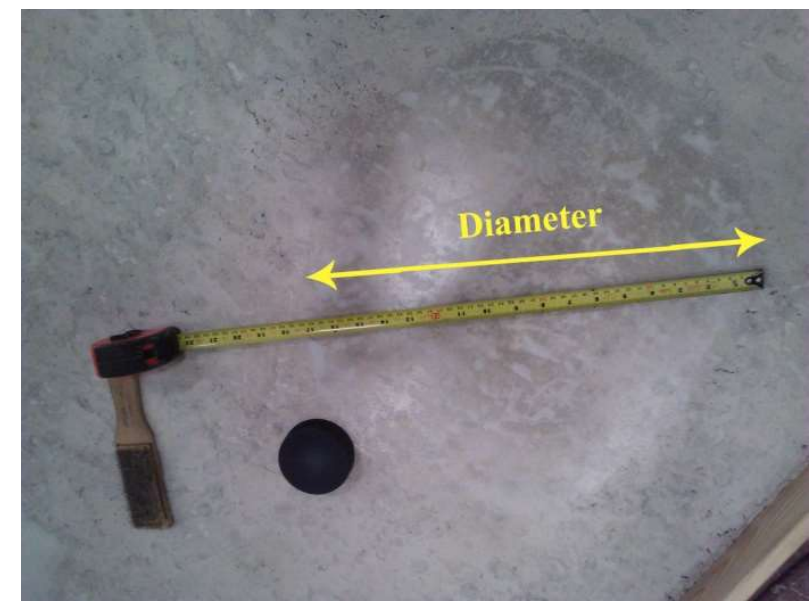

(b) Typical circle.

Fig. 4: Surface Roughness Test.
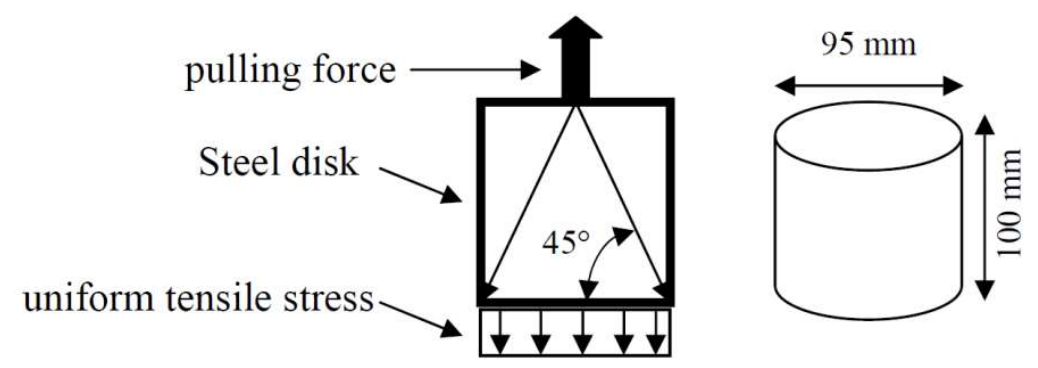

(a) Expected uniform stress distribution under disk No.1.

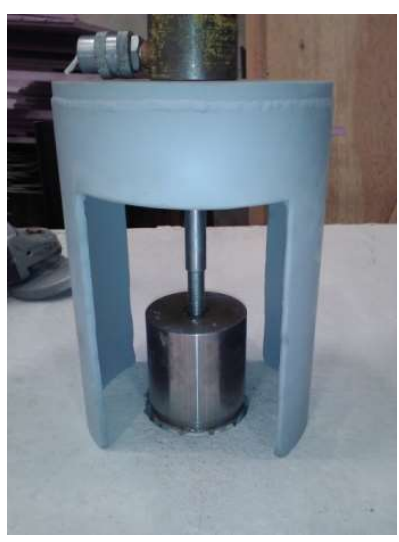

(b) Disk No. 1 (thickness $=100 \mathrm{~mm}$ ).

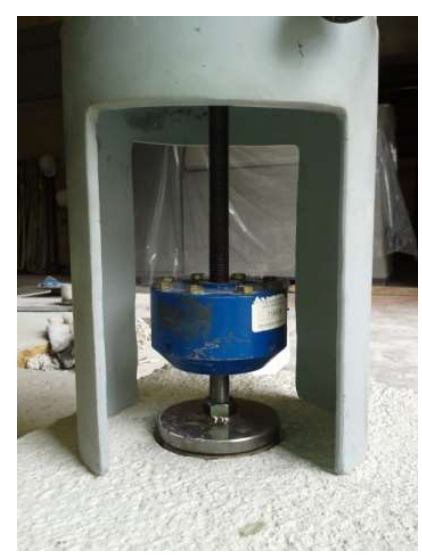

(c) Disk No. 2 (thickness $=10 \mathrm{~mm}$ ).

Fig. 5: Steel disks for the pull-off tests. 


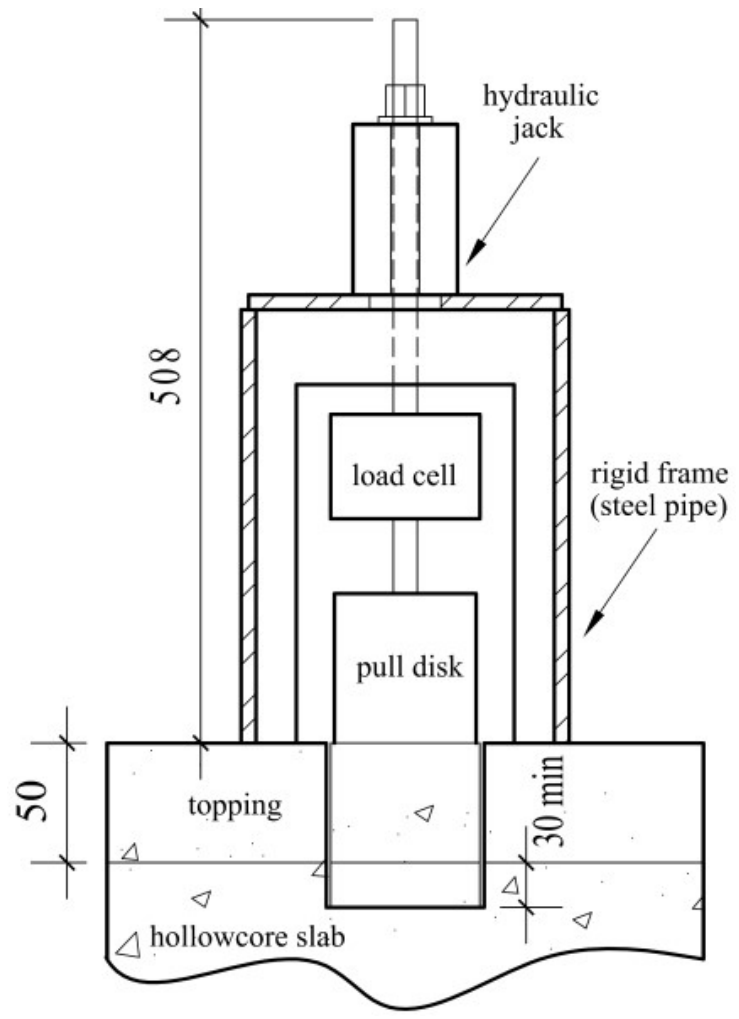

Fig. 6: Pull-off apparatus (dimensions in $\mathrm{mm}$ ). 


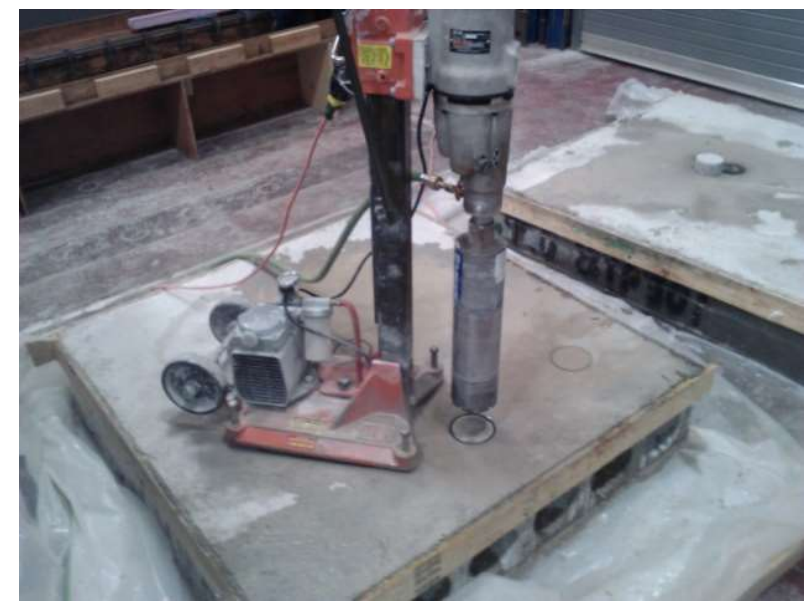

(a) Core drilling.

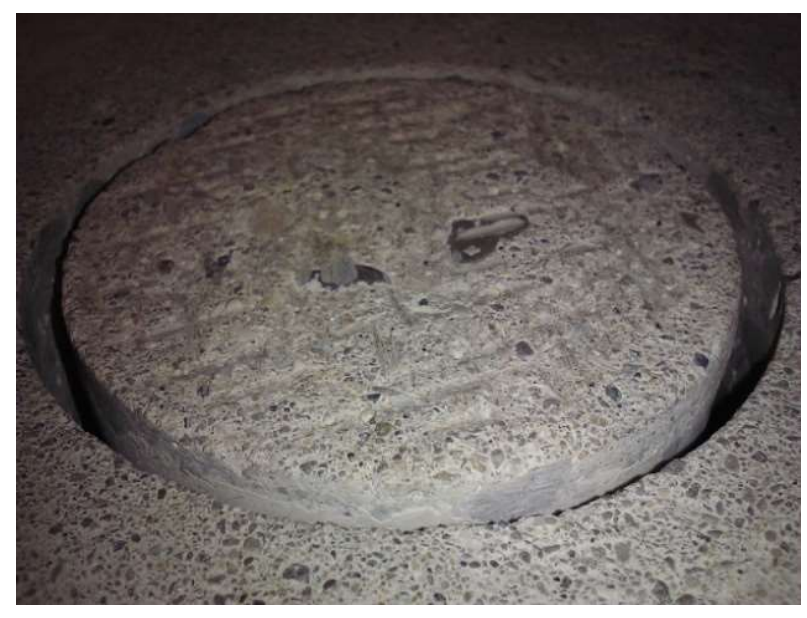

(c) Roughening of core surface.

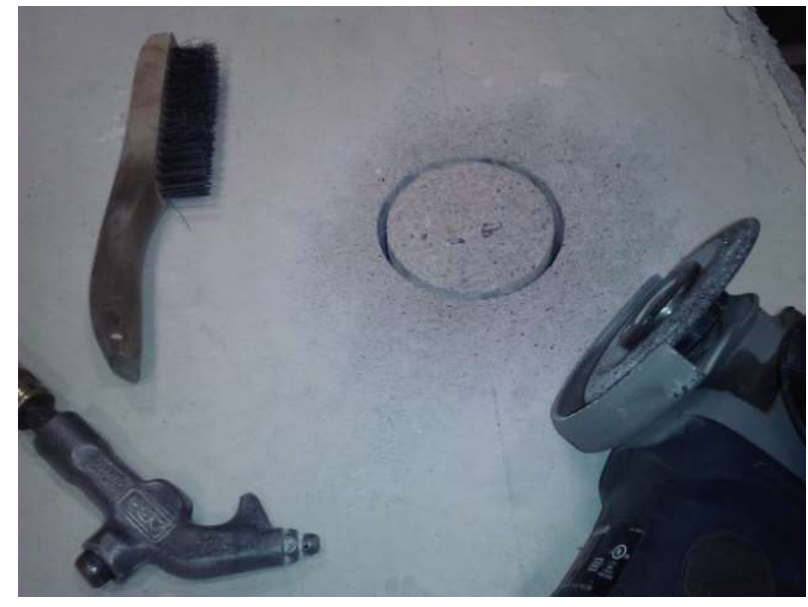

(b) Core cleaning.

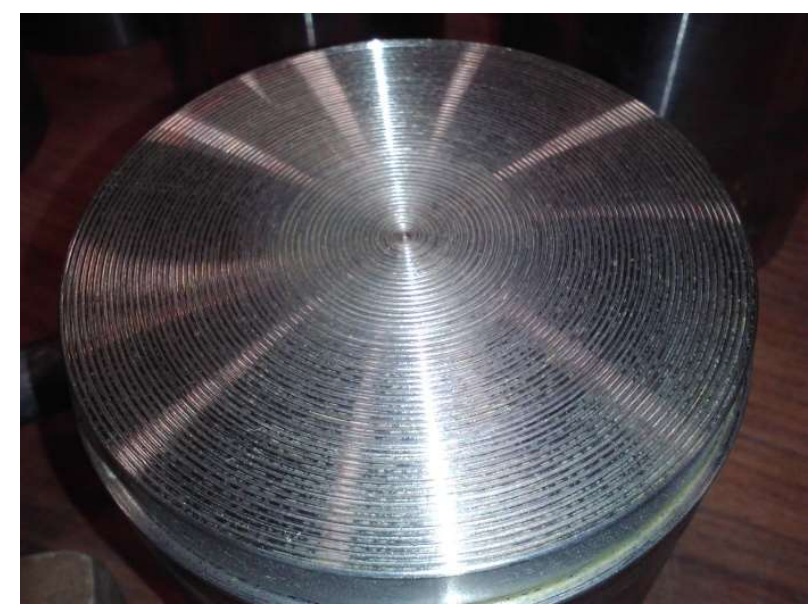

(d) Roughening of disk bottom surface.

Fig. 7: Core drilling and roughening process. 


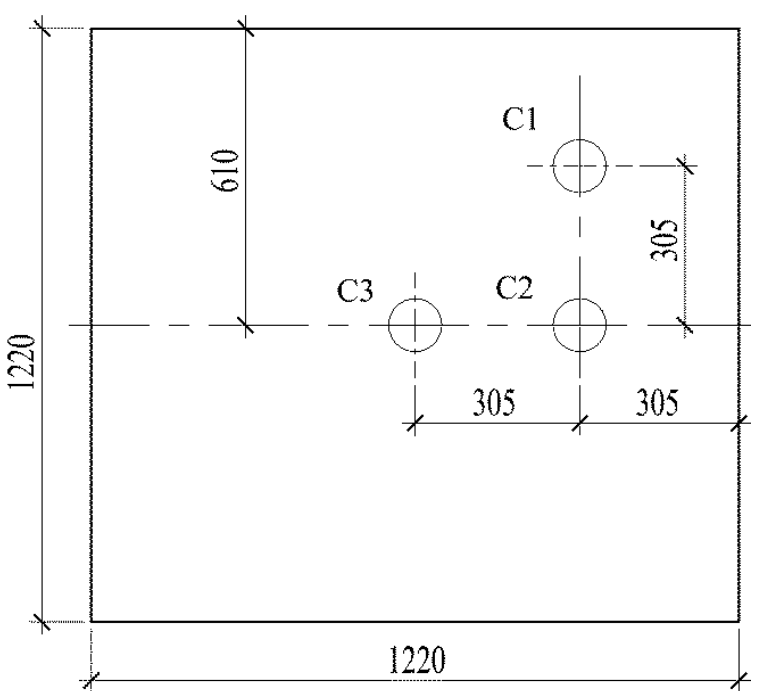

(a) $1^{\text {st }}$ shipment.

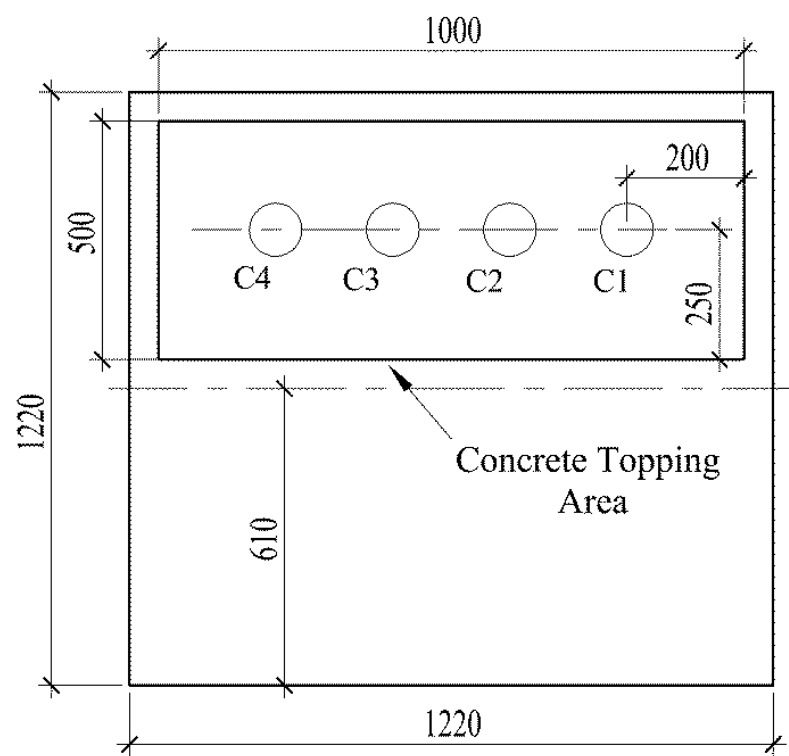

(b) $4^{\text {th }}$ shipment.

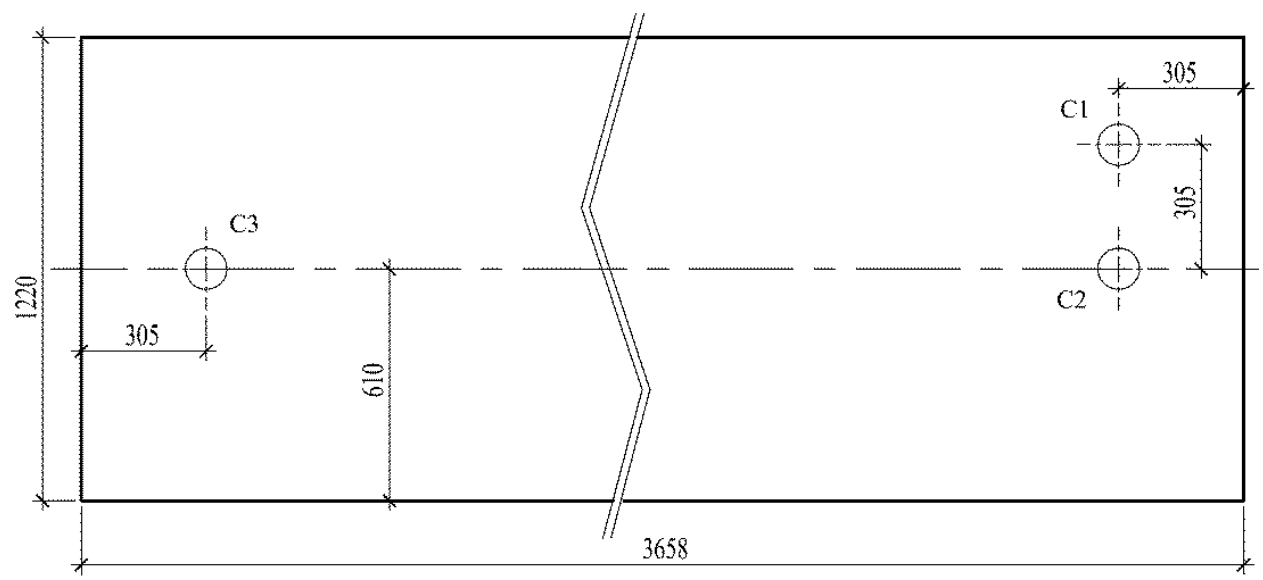

(c) $2^{\text {nd }}$ shipment.

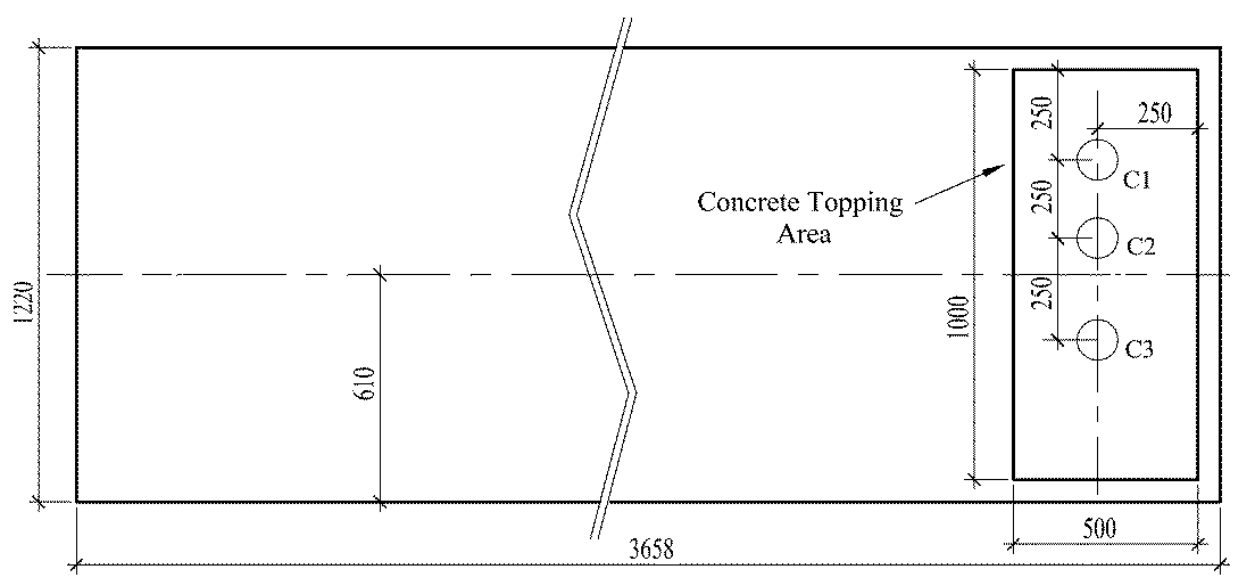

(d) $3^{\text {rd }}$ shipment.

Fig. 8: Core Locations (dimensions in $\mathrm{mm}$ ). 


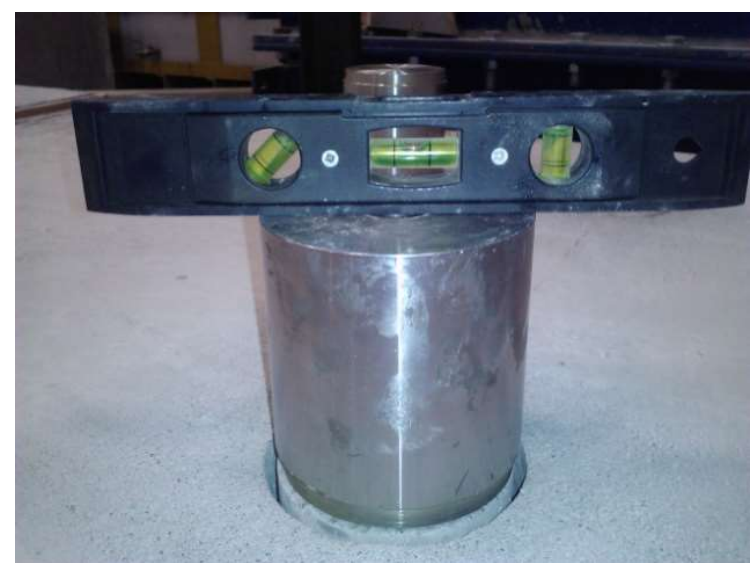

(a) Bonding of the steel disk using epoxy.

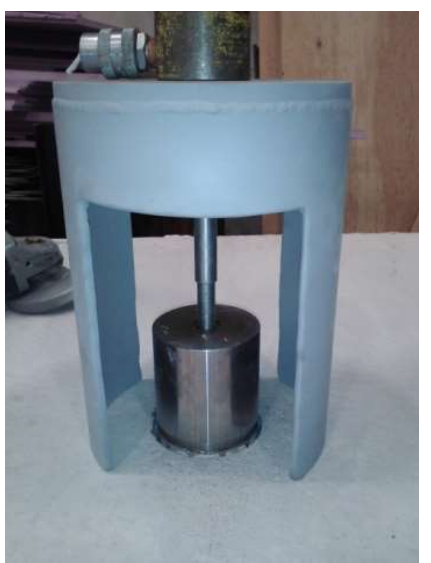

(b) Disk attachment to pull-off apparatus.

Fig. 9: Pull-off test preparation.

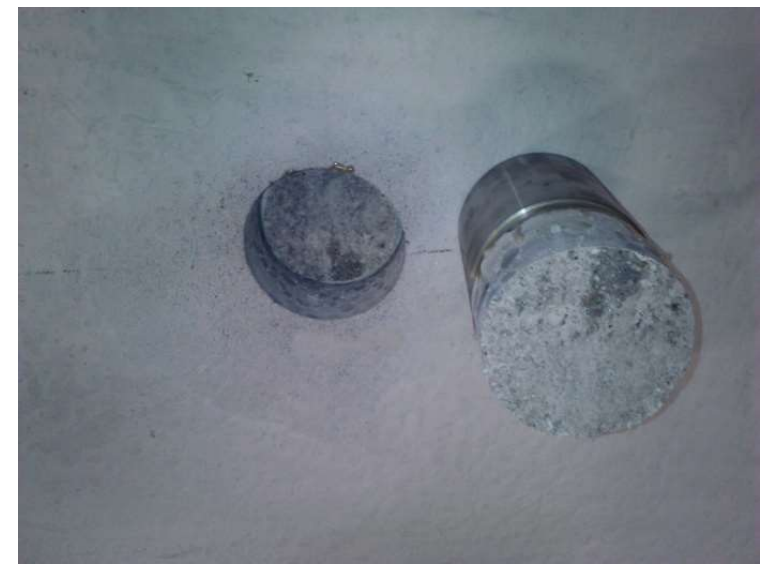

(a) Interface failure (I).

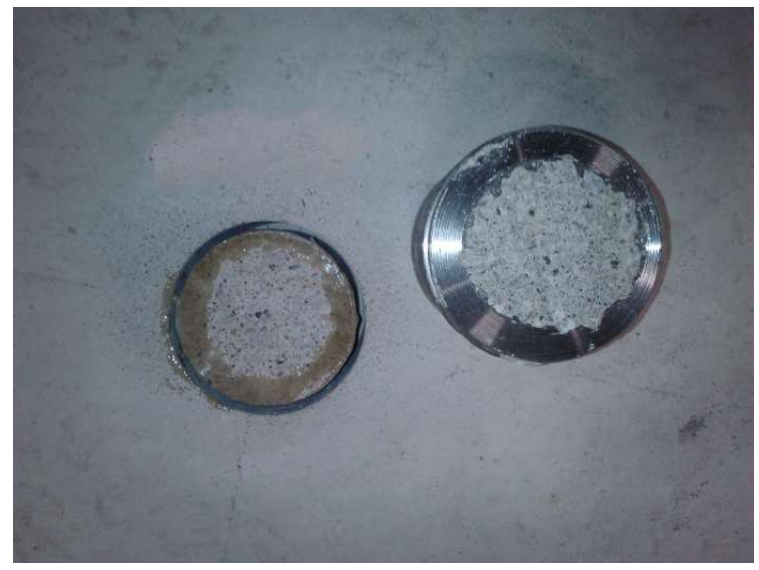

(b) Epoxy failure (X).

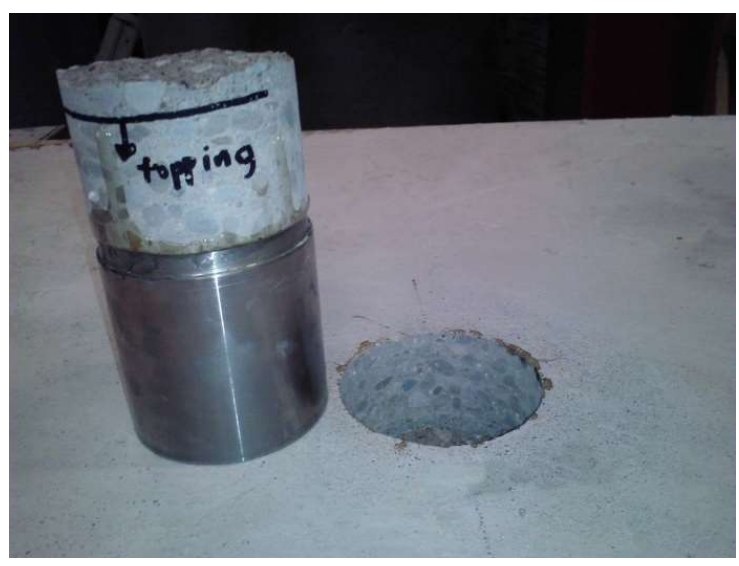

(c) Hollowcore slab failure $(\mathrm{H})$.

Fig. 10: Failure types. 


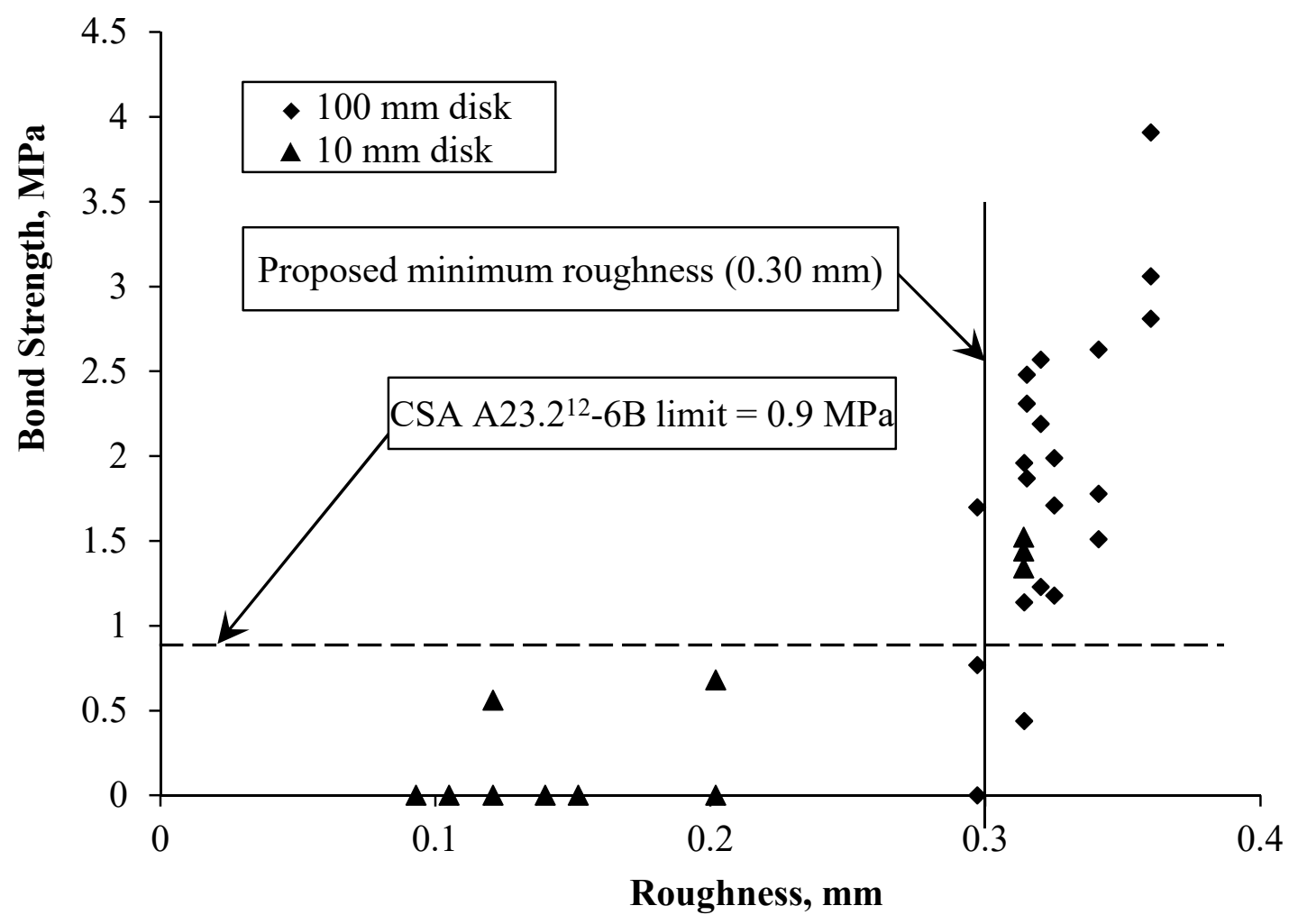

Fig. 11: Pull-off test results in terms of hollowcore slab surface roughness 


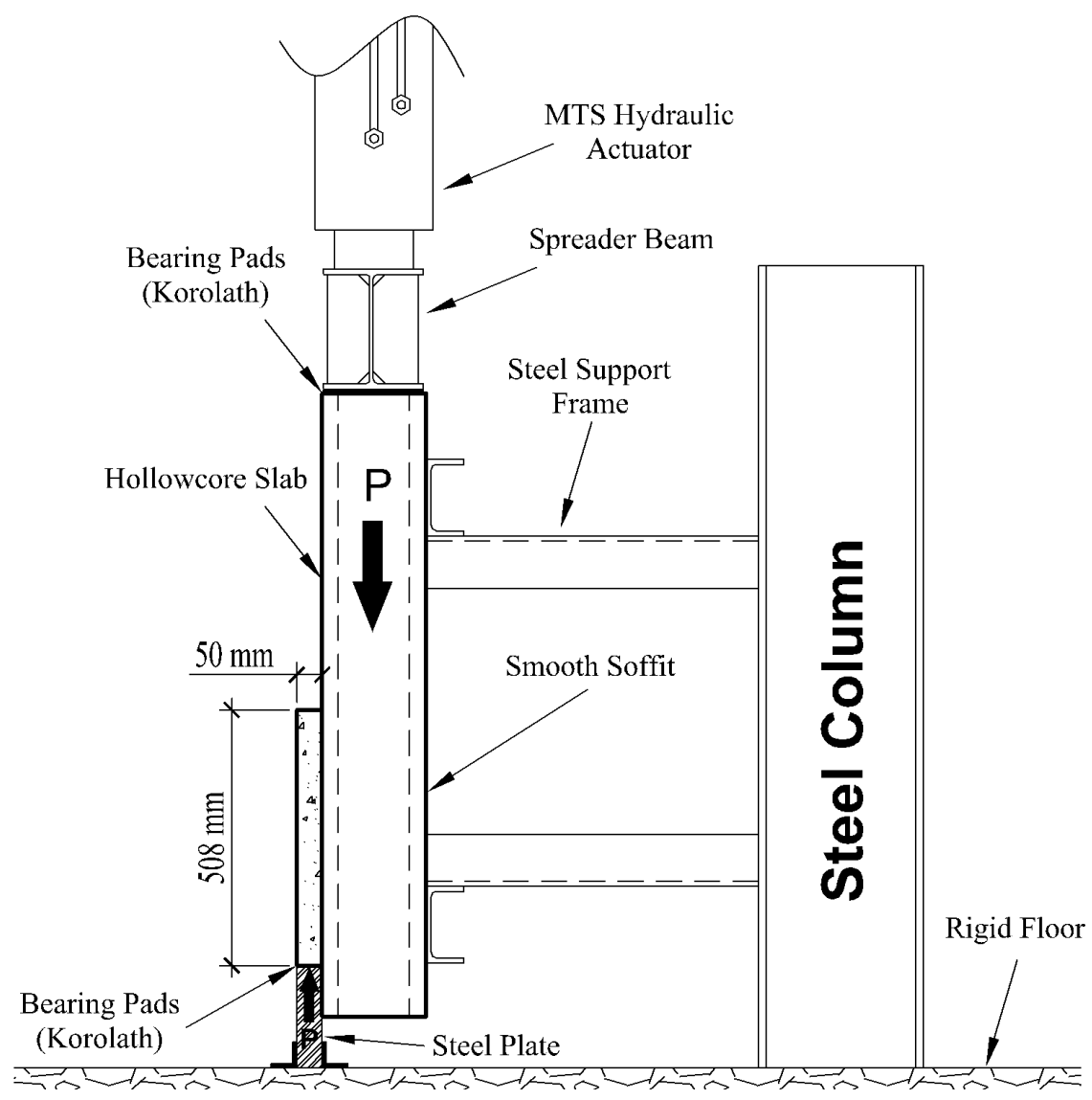

(a) Schematic.

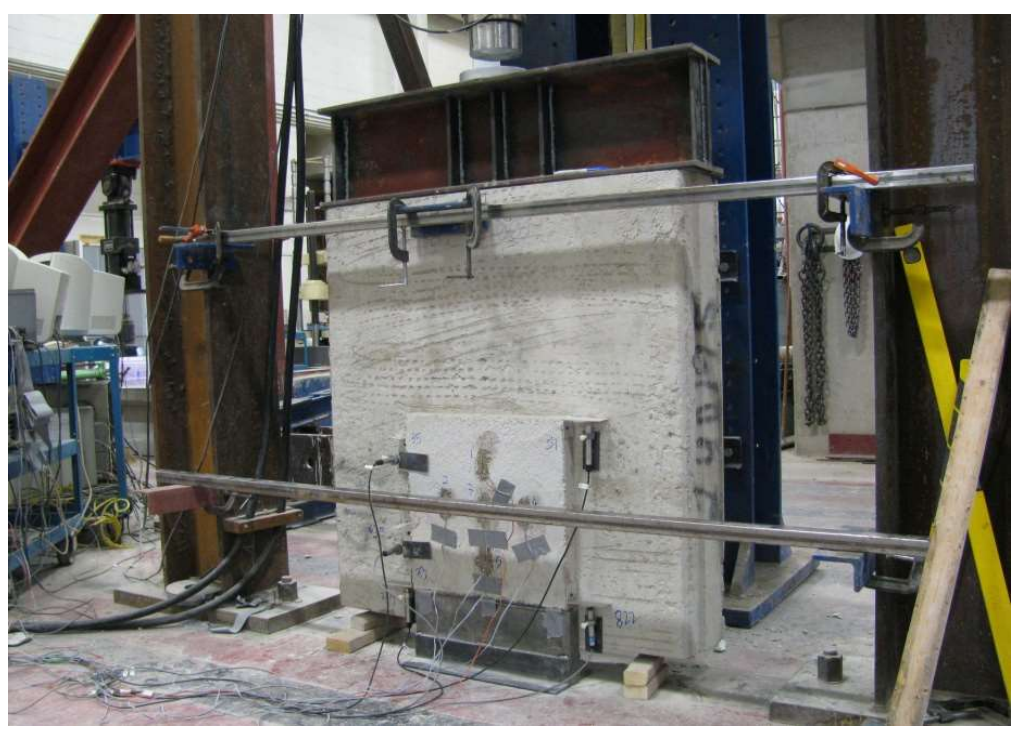

(b) Photo.

Fig. 12: Push-off test setup. 


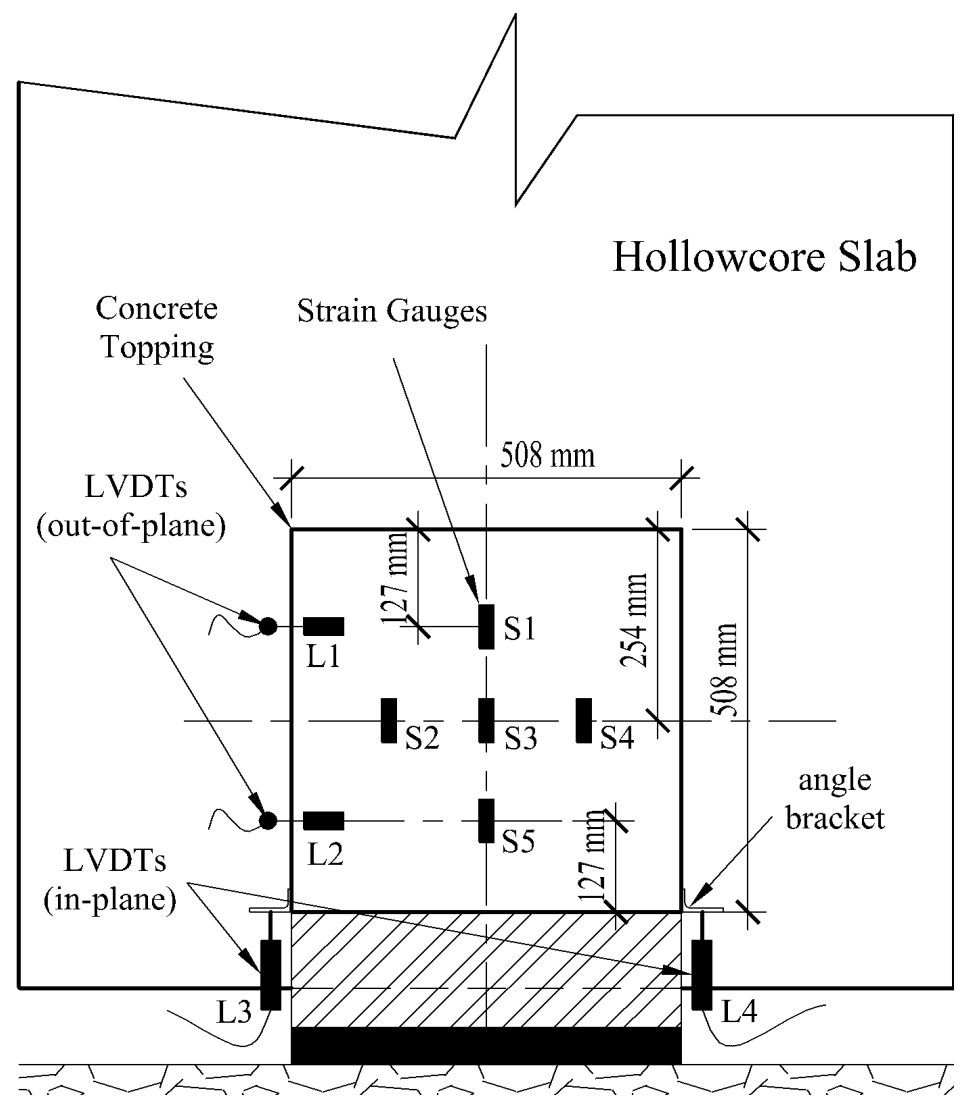

Fig. 13: Push-off test instrumentation.

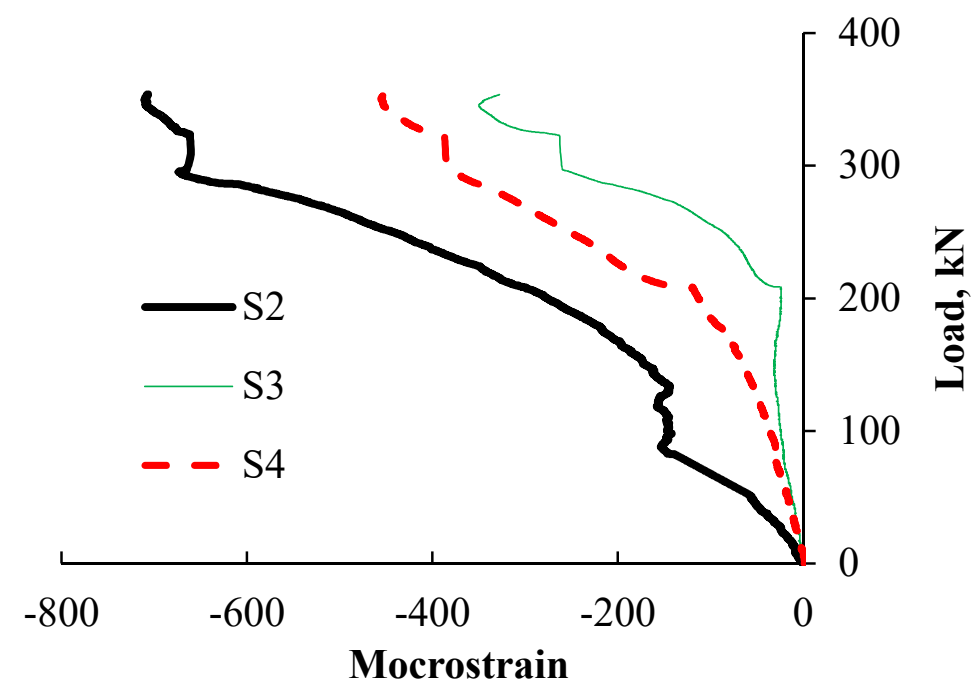

Fig. 14: Readings of strain gauges S2, S3 and S4 for SMA1-2 


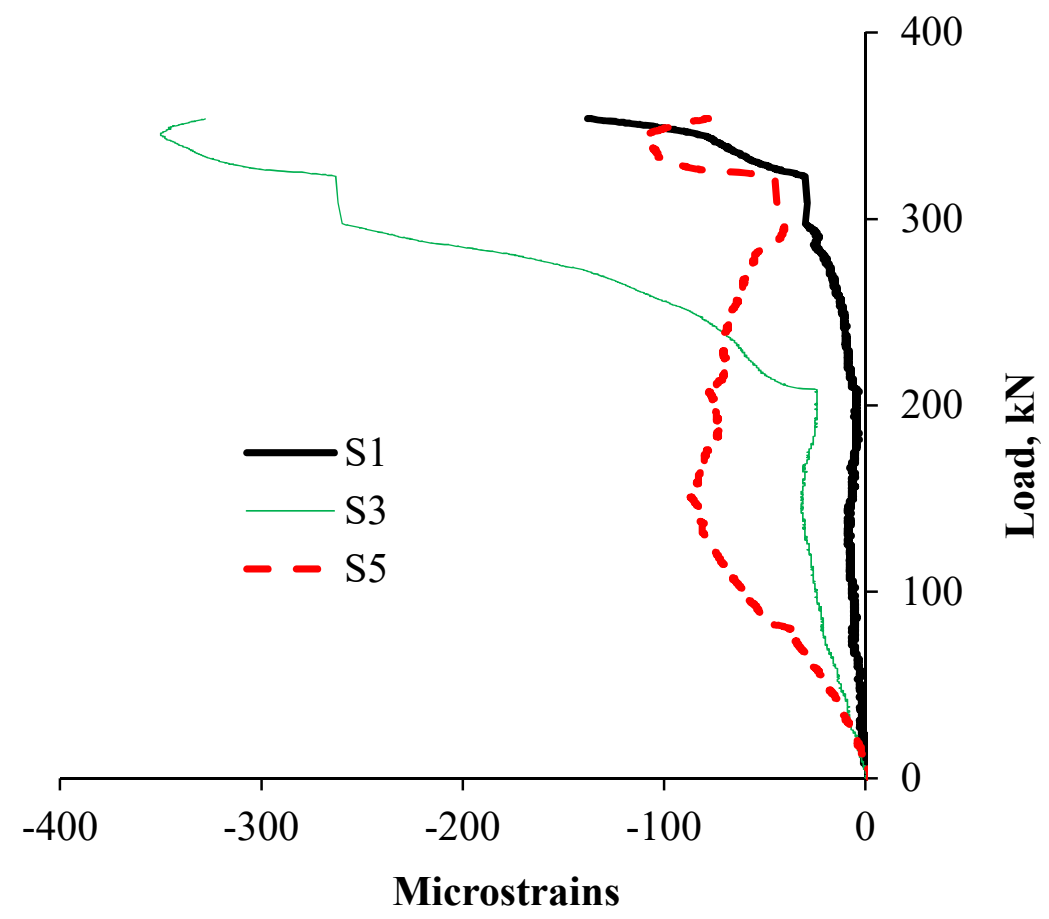

Fig. 15: Readings of strain gauges S1, S3 and S5 for SMA1-2.

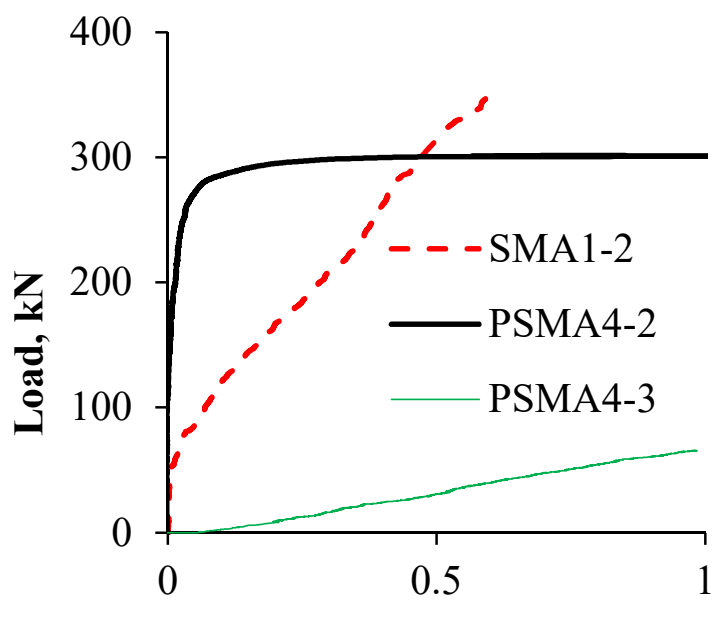

Slip, mm

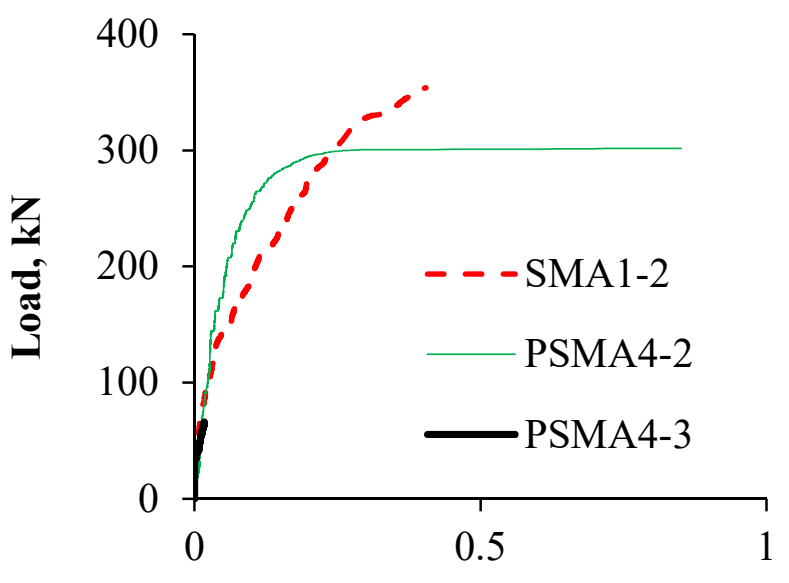

Peel, mm
(a) Load-slip results.
(b) Load-peel.

Fig. 16: Slip and peel results. 


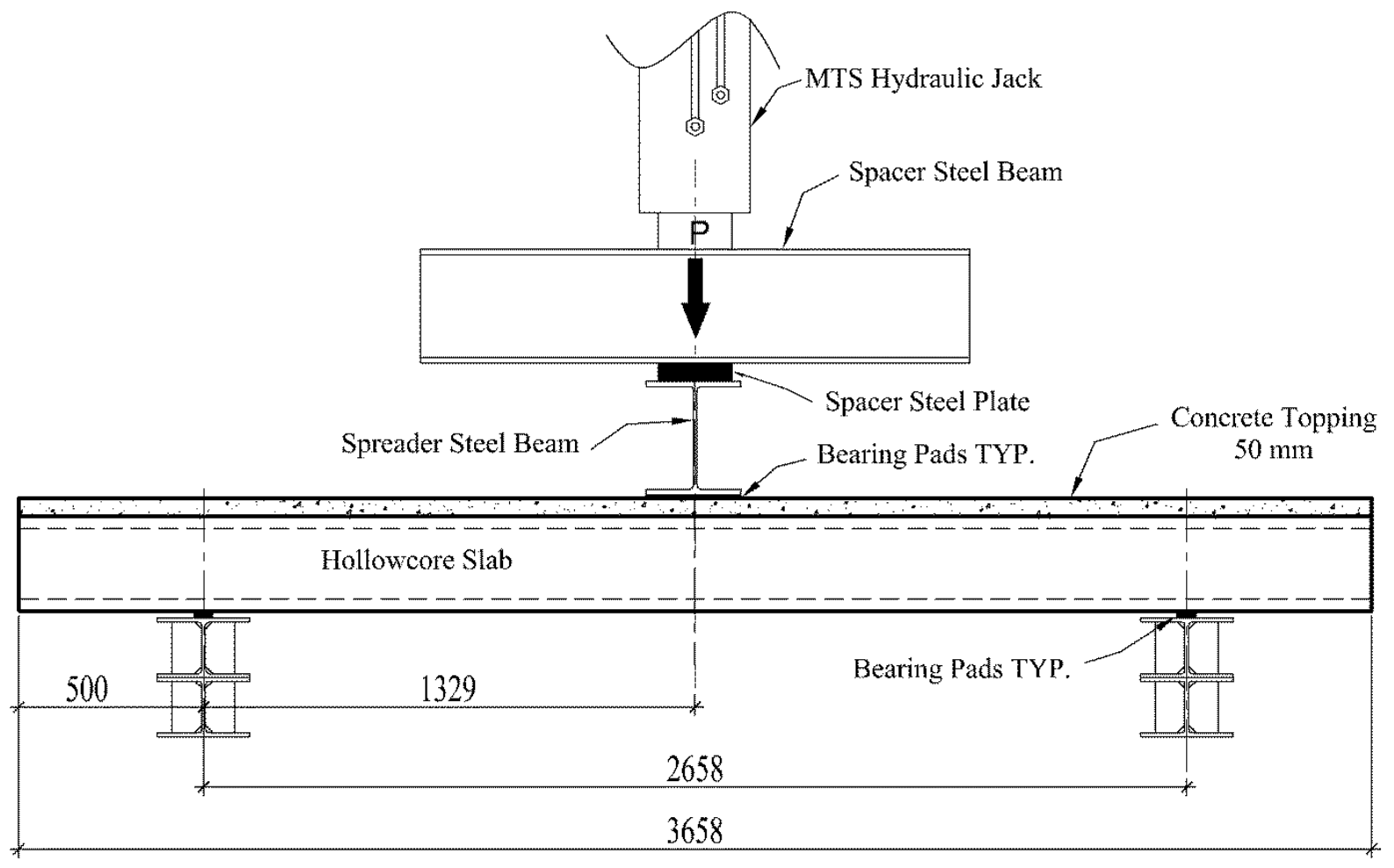

(a) Schematic (dimensions in $\mathrm{mm}$ ).

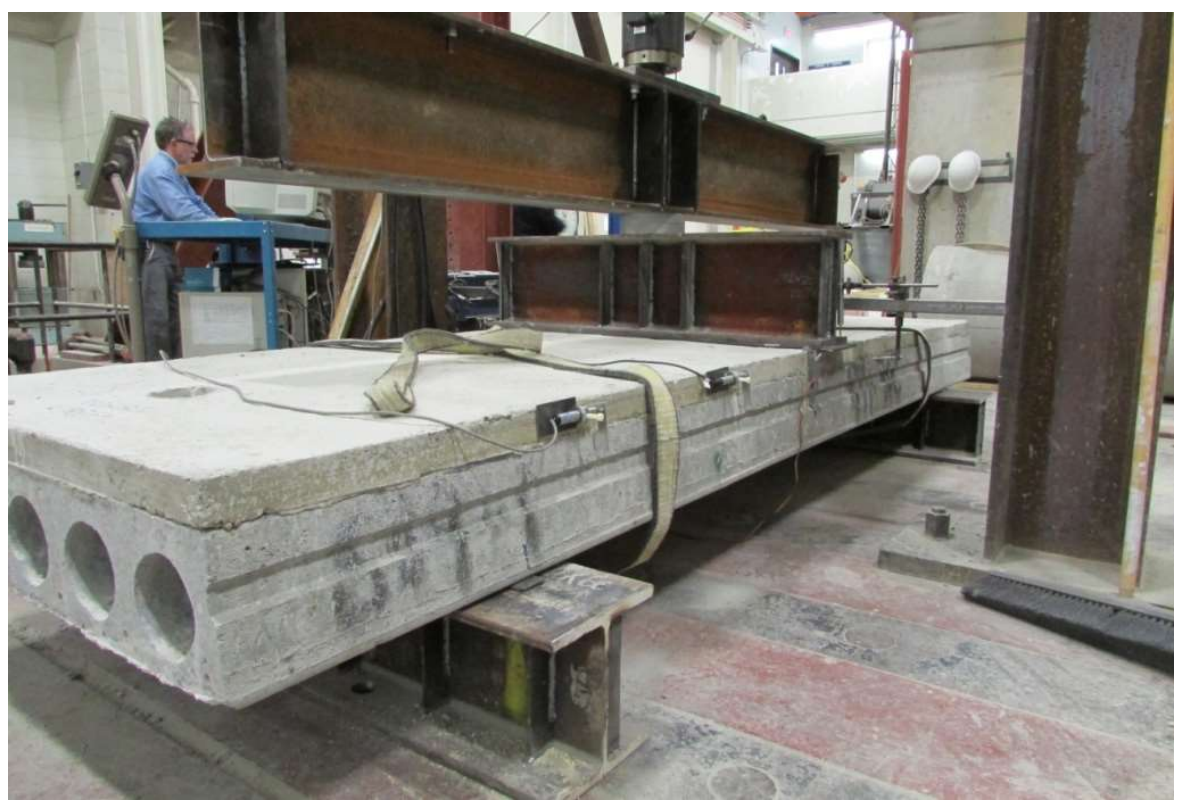

(b) Photo.

Fig. 17: Full-scale test setup. 

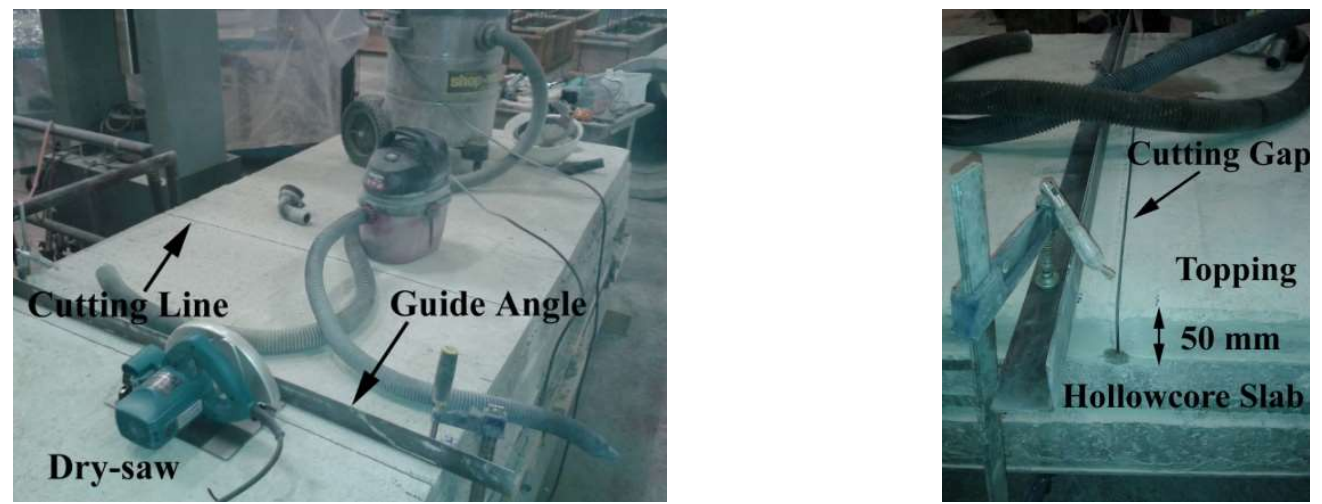

(a) Saw cutting of the concrete topping.

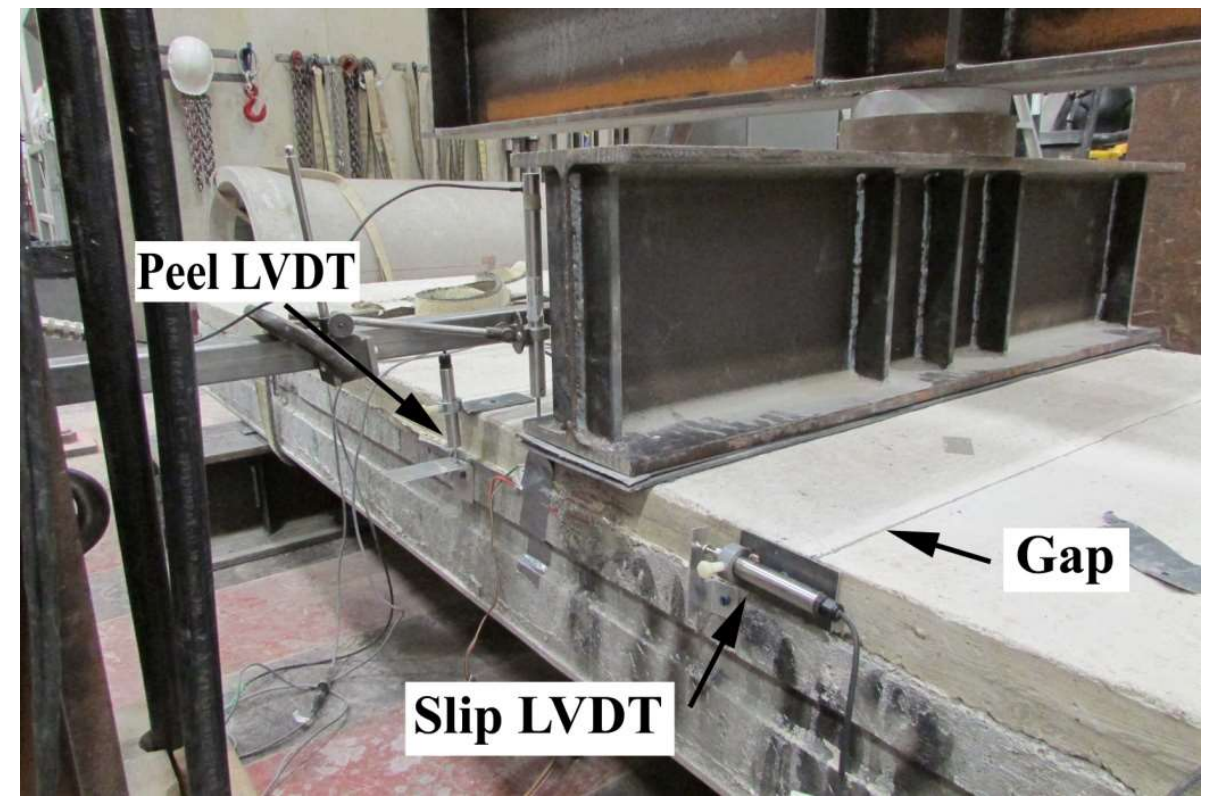

(b) Test setup.

Fig. 18: Slabs with gap in their topping (FMA2-2 and FMB2-1). 


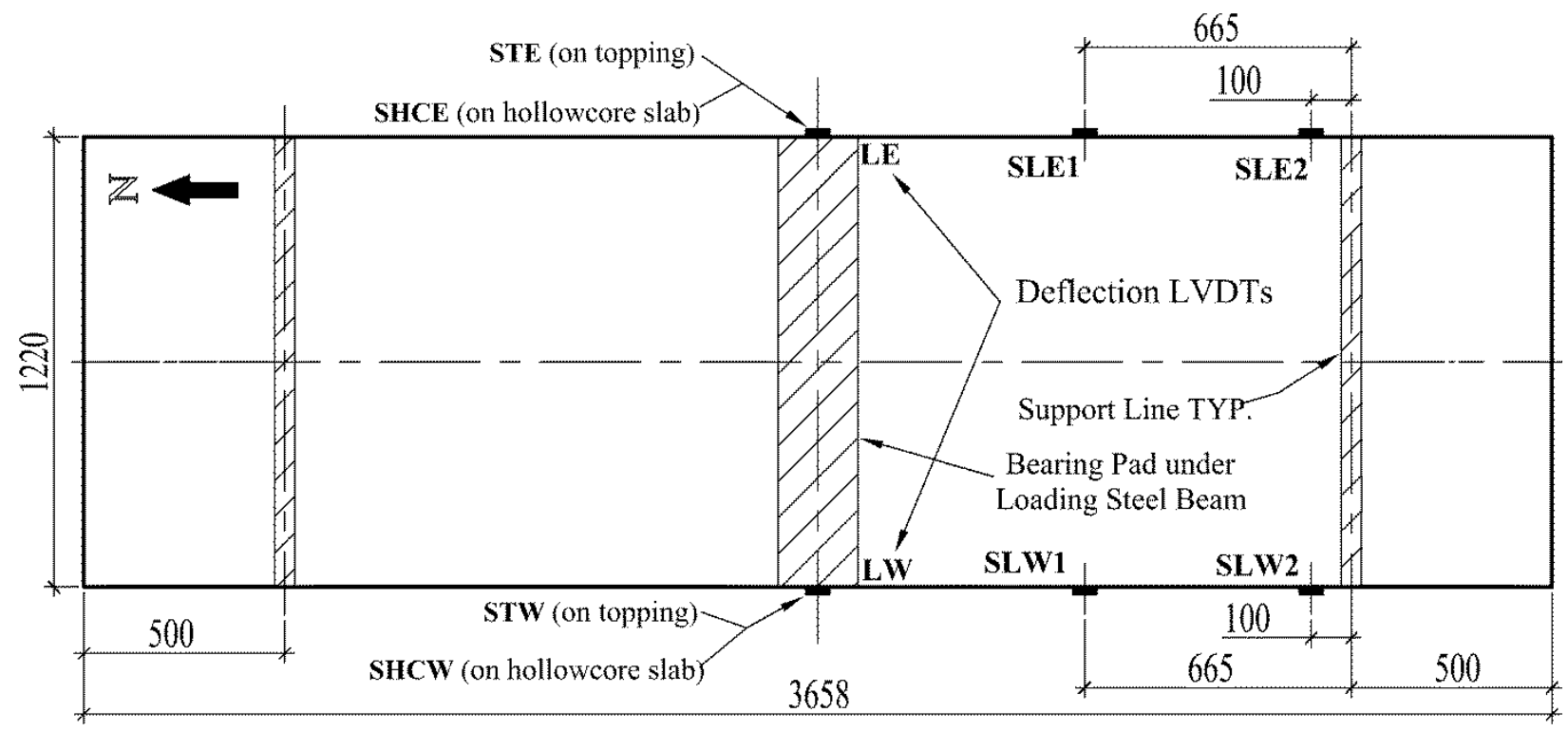

(a) Typical slab.

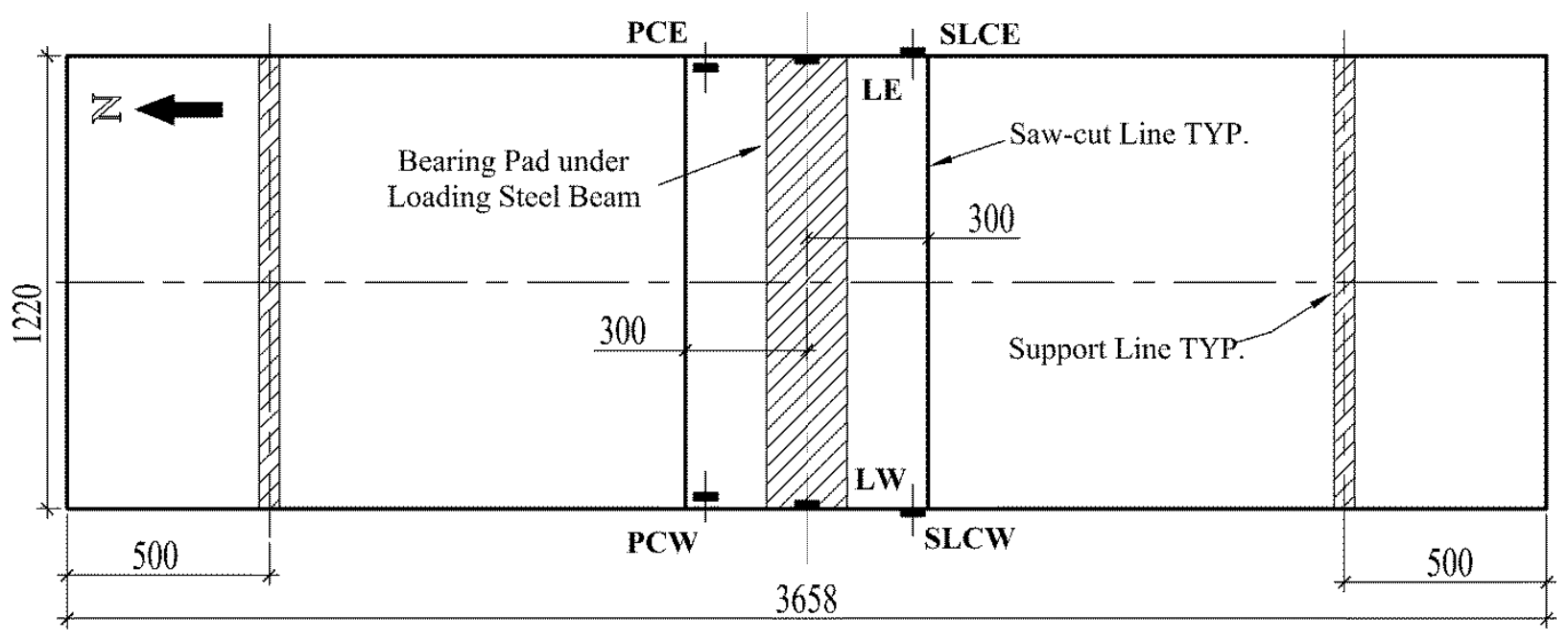

(b) Slabs with gaps in their topping.

Fig. 19: Instrumentation layout (dimensions in $\mathrm{mm}$ ). 


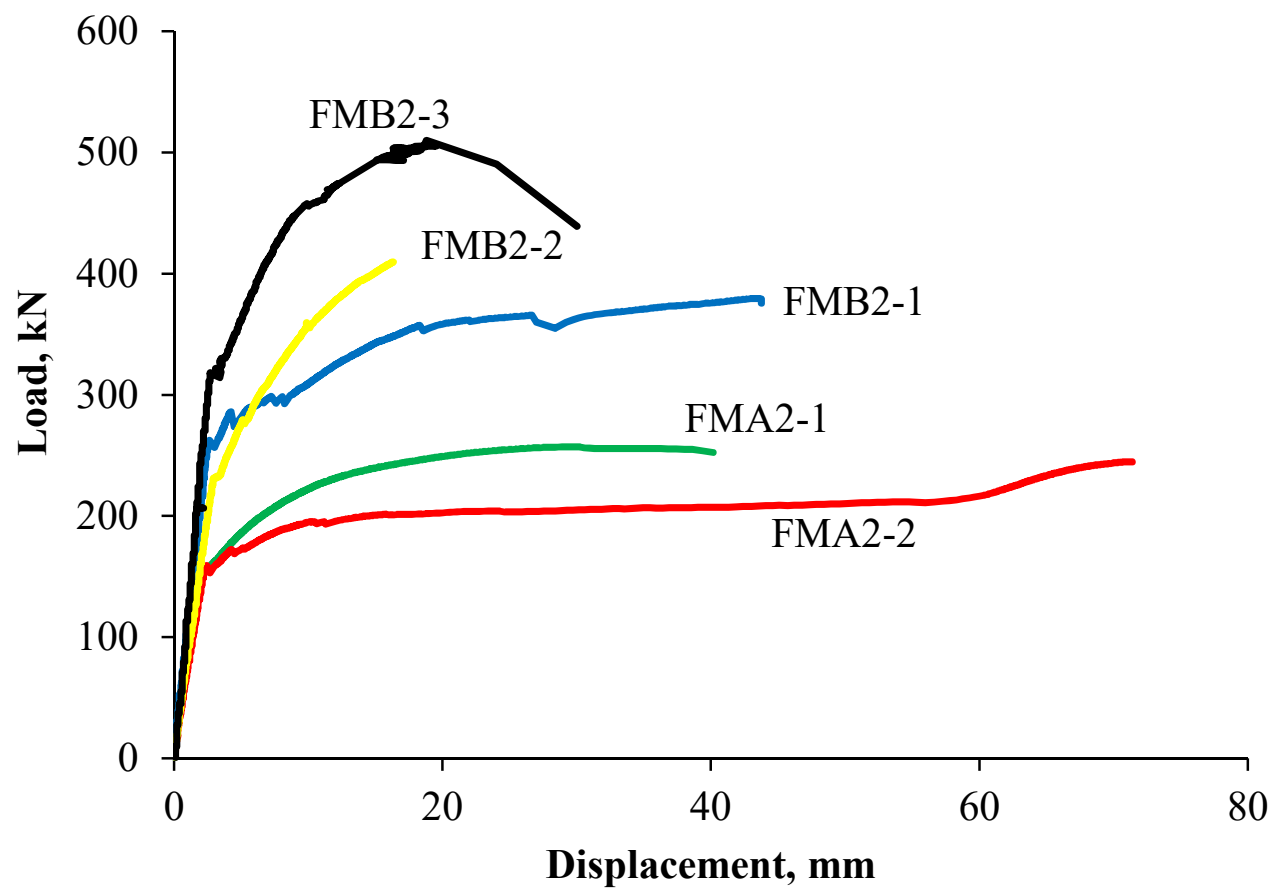

Fig. 20: Load-deflection test results. 


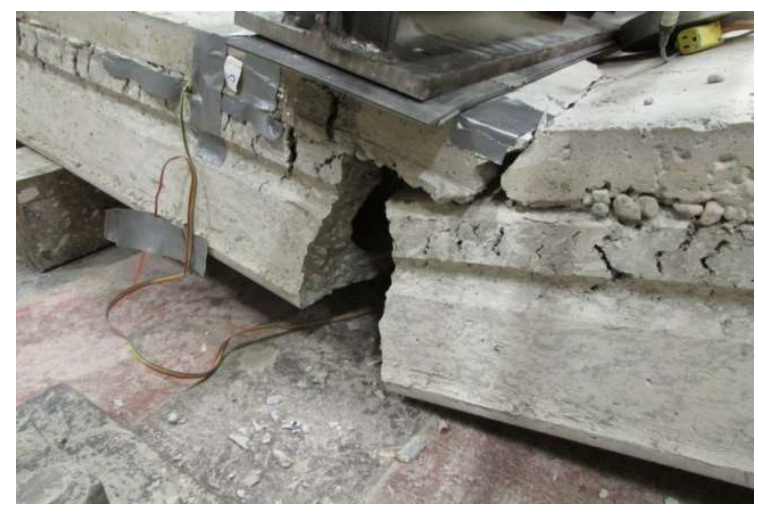

(a) FMA2-1 (strand rupture).

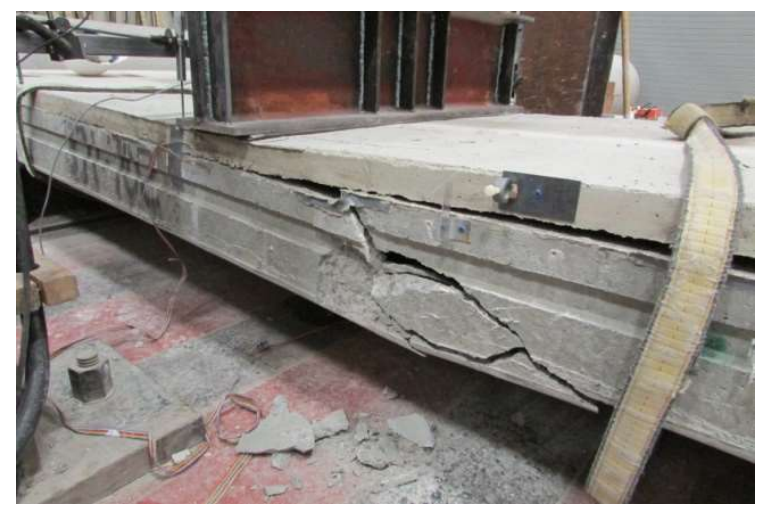

(c) FMB2-1 (flexural shear failure).

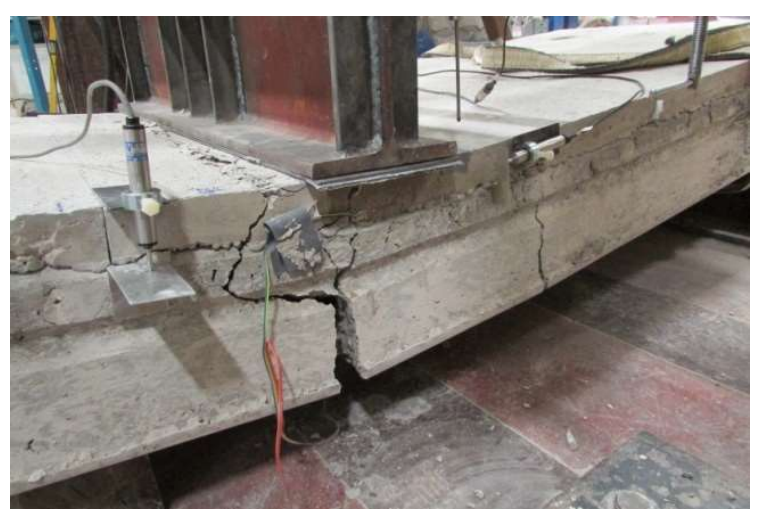

(b) FMB2-2 (strand rupture).

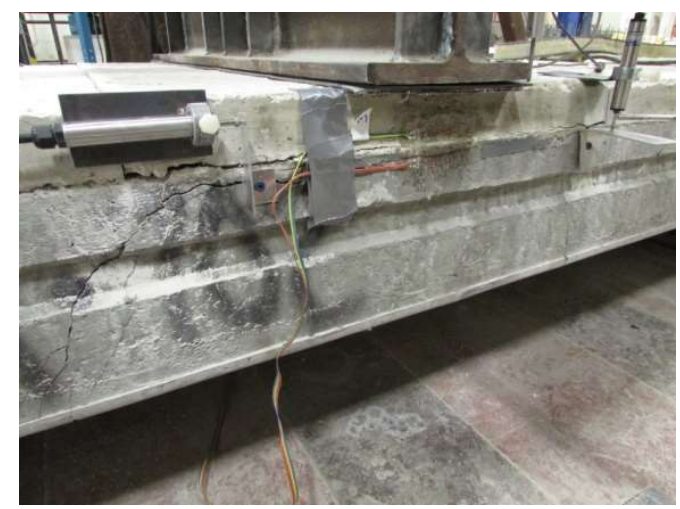

(d) FMB2-2 (flexural shear failure).

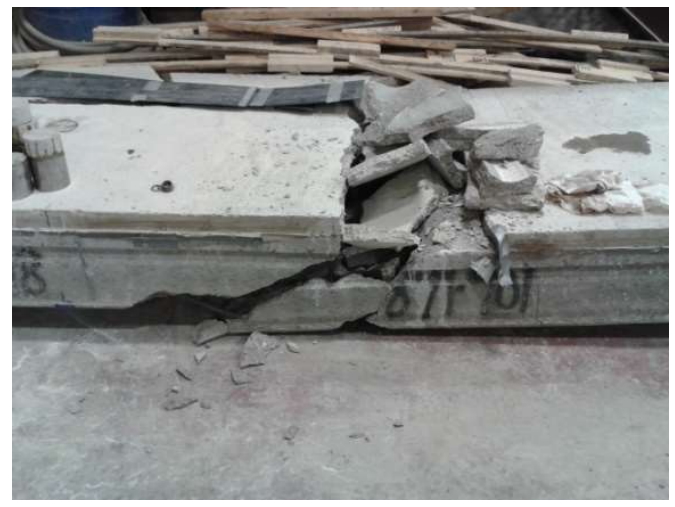

(e) FMB2-3 (flexural shear failure).

Fig. 21: Failure modes. 


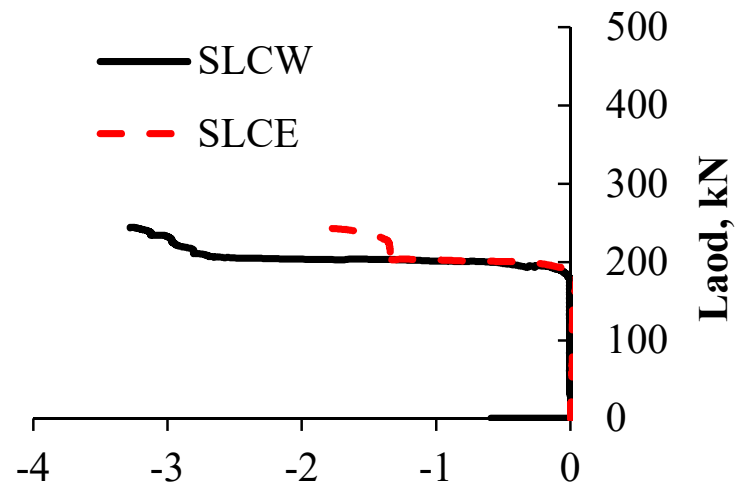

Slip, mm

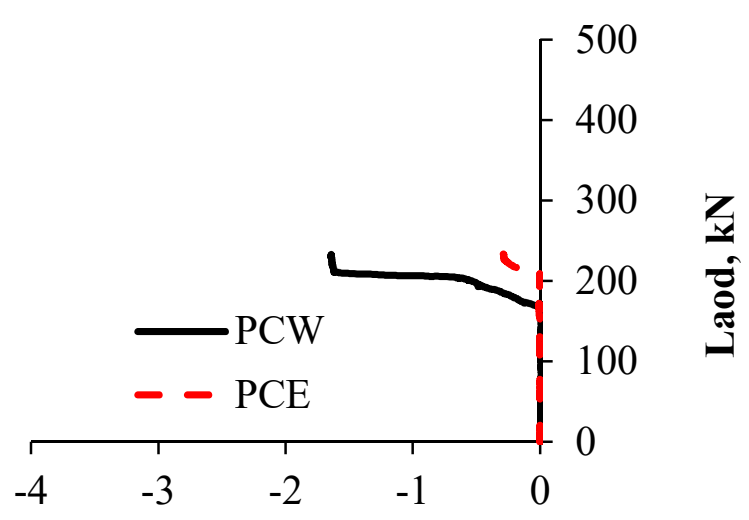

(a) FMA2-2.
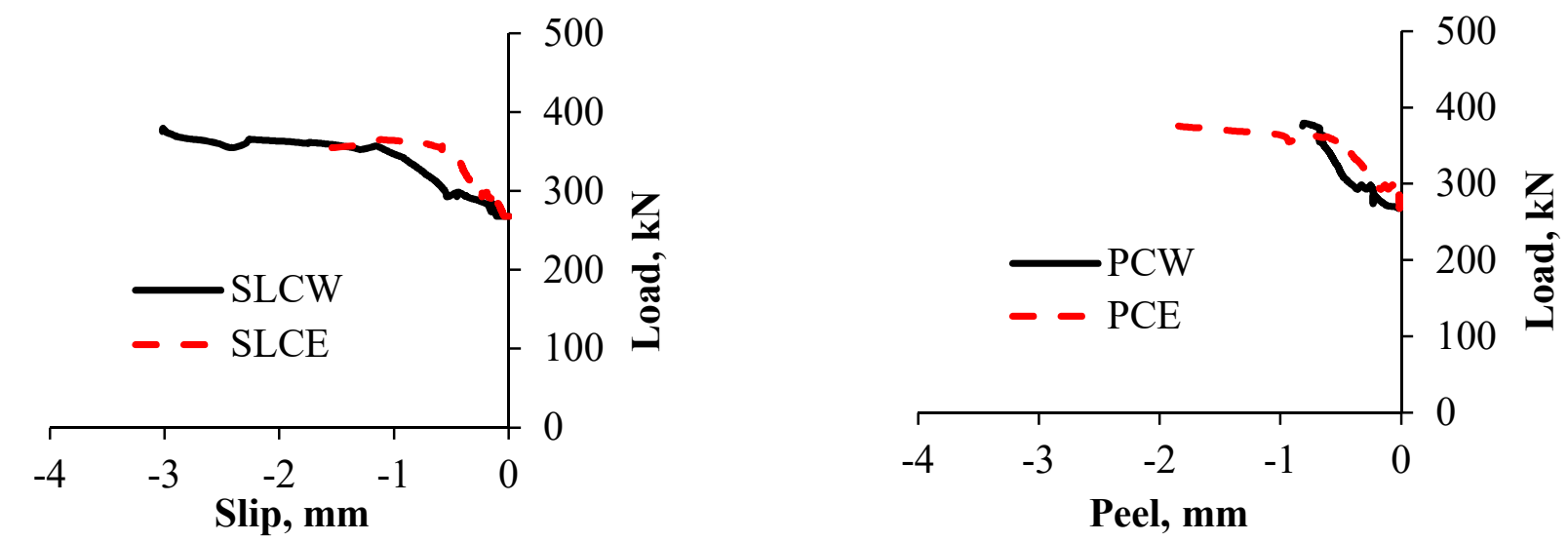

(b) FMB2-1.

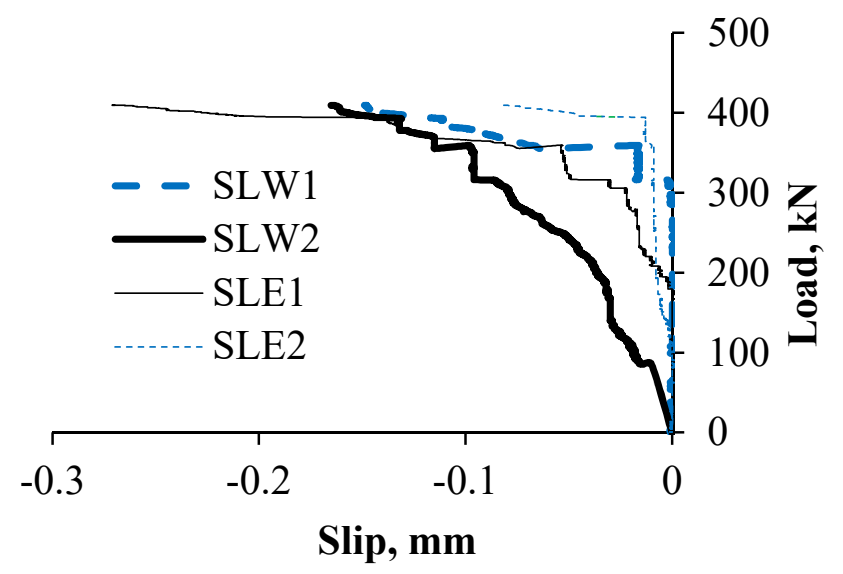

(c) Slab FMB2-2.

Fig. 22: Slip and peel measurements. 


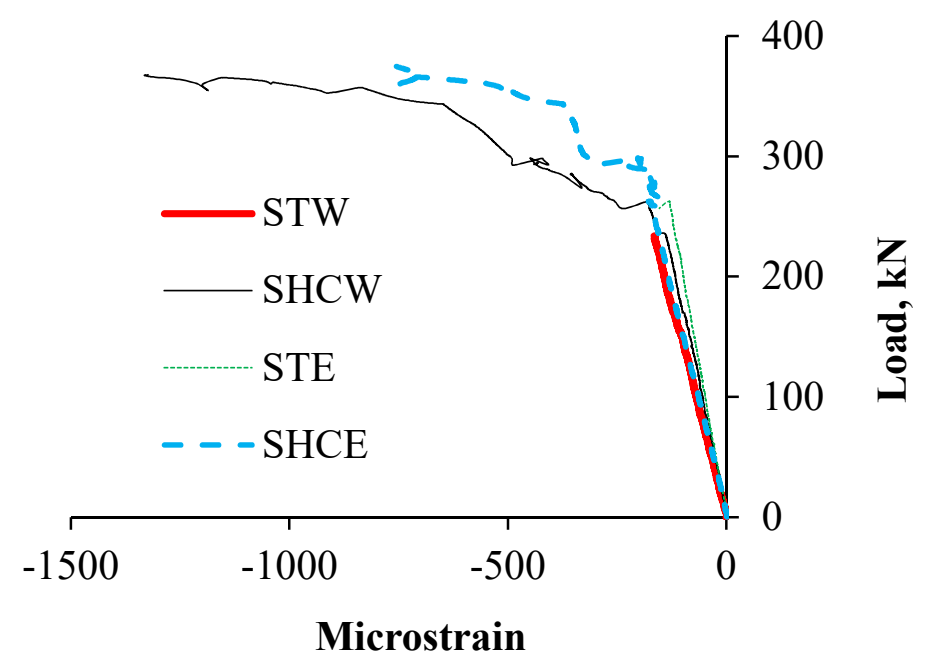

Fig. 23: Strain readings for FMB2-1.

18. 